\title{
Educação Pré-Escolar, Distorções e Crescimento Econômico ${ }^{*}$
}

\author{
Bruno Ricardo Delalibera $^{\dagger}$, Pedro Cavalcanti Ferreira ${ }^{\ddagger}$
}

\author{
Sumário: 1. Introdução; 2. O modelo; 3. Metodologia; 4. Resultados; 5. Análise Quantitativa; \\ 6. Sensibilidade do modelo; 7. Conclusão; A. Apêndice. \\ Palavras-chave: Educação, Distorções Econômicas, Crescimento Econômico. \\ Códigos JEL: $\quad$ 011, 040, 057.
}

O objetivo deste trabalho é entender, pela ótica da educação, a divergência da renda per capita e a convergência dos anos de escolaridade entre os países da África Subsaariana e os países europeus entre 1960 e 2010. Para tanto, o presente trabalho utiliza um ferramental de equilíbrio geral, no qual existem dois setores na economia e consumidores homogêneos que escolhem consumo, educação formal e educação pré-escolar. De acordo com os resultados do trabalho, apesar da educação pré-escolar para os países subsaarianos ter evoluído entre 1960 e 2010 os países subsaarianos em 2010 não alcançaram essa educação préescolar que os europeus tinham em 1960. Além disso, a produtividade total dos fatores e a expectativa de vida foram fatores importantes para compreender esse aumento da distância da renda per capita entre os países subsaarianos e os europeus. Por fim, o principal resultado em termos de política educacional é que políticas de incentivo à educação pré-escolar são mais eficazes em impactar a renda per capita do que políticas de incentivo à formal.

The objective of this work is to understand, from the perspective of education, the divergence in per capita income and the convergence of schooling among the subSaharan and European countries between 1960 and 2010. This study uses a general equilibrium model where there are two sectors in the economy and homogeneous consumers who choose consumption, formal education and early childhood education. According to the results of the work, despite the evolution of early childhood education for the countries of sub-Saharan those countries did not reach early childhood education that Europeans had in 1960. Moreover, the life expectation and total factor productivity were important for understanding the increasing the distance in per capita income between sub-Saharan and European countries. Finally, the main result in terms of educational policy is that policies to encourage early childhood education are more effective to increase the per capita income than policies encouraging formal education.

\footnotetext{
*Agradecemos aos comentários de Francisco Junqueira Moreira da Costa, Samuel Pessoa, Marcelo Santos, aos Participantes do $36^{\circ}$ encontro da SBE e as sugestões dos pareceristas anônimos. Além disso, Delalibera agradece o financiamento da Capes, e Ferreira o da Faperj e do CNPq/INCT.

†Escola de Pós-Graduação em Economia-Fundação Getúlio Vargas. R. Praia de Botafogo, 190, Botafogo, Rio de Janeiro-RJ. CEP 22250-900. Fone: (21) 98286-4895. E-mail: bruno. delalibera@fgvmail . br

${ }^{\ddagger}$ Escola de Pós-Graduação em Economia-Fundação Getúlio Vargas. E-mail: pedro.ferreira@fgv.br
} 


\section{INTRODUÇÃO}

Nas últimas décadas observa-se uma convergência nos anos de escolaridade entre países ricos e pobres, mas não se observa uma convergência na renda per capita entre esses países (Restuccia \& Vandenbroucke, 2013c). Particularmente, ao analisar os dados da Penn World Table e do Barro-Lee Educational Attainmennt Dataset para os países da África subsaariana e da Europa no período de 1960 a 2010, nota-se que a renda per capita divergiu entre os dois grupos de países, apesar de haver uma convergência nos anos médio de escolaridade entre os grupos.

Uma explicação para esse resultado aparentemente contraditório é que além dos anos de escolaridade também existem outros fatores incorporados na formação do capital humano dos indivíduos que elevam a produtividade do trabalhador e, logo, a renda. Um exemplo é o investimento educacional que abrange a primeira parte da vida do agente.

O investimento na primeira infância favorece o desenvolvimento intelectual dos indivíduos e, logo, a ascensão socioeconômica. Em Rolnick e Grunewald (2003) e Schweinhart et al. (2005) o retorno do investimento na pré-escola é alto tanto para o setor privado, mediante o aumento da produtividade marginal do capital, quanto para o setor público, por meio da externalidade gerada com a melhoria socioeconomica dos agentes. Heckman, Moon, Pinto, Savelyev e Yavitz (2010) mostram que o retorno social do programa Perry Preschool ${ }^{1}$ é entre $7 \%$ e $10 \%$, considerado alto comparativamente a outros investimentos. Outros estudos enfatizam que os primeiros anos de vida são cruciais para a formação das conexões cerebrais que captam os diferentes estimulos do ambiente em que a criança está inserida, impactando no seu desenvolvimento intelectual, na personalidade e na sua conduta social (Irwin, Siddiqi \& Hertzman, 2007; Myers \& de San Jorge, 1999; Young, 1996). Em Heckman (2011) nota-se que a desigualdade econômica e intelectual entre os indivíduos começa na primeira infância, pois o diferencial de investimentos com essa fase se transforma em desigualdade de habilidade cognitiva e não cognitiva. ${ }^{2}$ Nesse sentido, países que tivessem baixo investimento na primeira infância, teriam a priori uma baixa produtividade dos seus indivíduos o que poderia refletir em uma menor renda per capita.

Apesar da importância dessa fase de ensino para o desenvolvimento econômico não existem medidas de educação pré-escolar para grande parte dos países, dificultando o estudo de determinantes de desigualdade de renda entre os países. Assim, mensurar a educação pré-escolar para países europeus e países da África Subsaariana para os anos de 1960 e 2010 é um dos desafios tratados neste trabalho.

Além do estudo voltado para a África Subsaariana e para a Europa, este trabalho também se afasta da literatura já existente ao unir o aumento dos incentivos educacionais ${ }^{3}$ como possível fator explicativo para a convergência nos anos de escolaridade e o investimento em educação da primeira infância que pode explicar a divergência da renda per capita entre esses dois grupos de países.

A educação pré-escolar é mensurada através de uma econometria estrutural realizada por meio de um modelo de equilíbrio geral, o qual é baseado nos artigos de Ferreira e Pessoa (2003, 2007). Existem dois setores na economia, um que produz bens de consumo e capital e outro que produz bens de educação, enquanto que os consumidores são homogêneos e escolhem consumo, educação formal e educação préescolar. Assim, os incentivos econômicos são calibrados endogenamente no modelo de forma a satisfazer o equilíbrio da economia.

\footnotetext{
${ }^{1}$ O programa Perry Preschool, realizado nos Estados Unidos na década de 60, tratou durante dois anos um grupo de crianças negras com 3 anos de idade e socioeconomicamente desfavorecidas. Este tratamento contou com aulas diárias e, além disso, com visitas semanais do professor à casa do aluno. O programa coletou dados, tanto do grupo de tratamento quanto do grupo de controle, das crianças até atingirem os 40 anos de idade.

${ }^{2} \mathrm{~A}$ habilidade não cognitiva é definida de forma ampla como determinação, auto estima, bom relacionamento social, baixa probabilidade de cometer um crime, perseverança, etc.

${ }^{3}$ Os incentivos educacionais afetam a escolha educacional dos agentes, pois reduzem o custo da educação. Esse custo da educação pode ser pensado de forma ampla como a compra de material escolar, o custo de se deslocar até a escola ou o pagamento de mensalidades. Ceteris paribus, quanto maior é o custo da educação, menor será a educação que o indivíduo irá adquirir.
} 
De acordo com os resultados do presente trabalho, entre 1960 e 2010 as distorções sobre a educação formal $^{4}$ reduziram aproximadamente $83 \%$ e $71 \%$ o custo educacional para os países subsaarianos e europeus, respectivamente. Logo, um aumento dos incentivos para a educação formal nos países da África Subsaariana relativamente aos países da Europa pode ajudar a entender a convergência dos anos de escolaridade entre esses dois grupos.

Grande parte da literatura que explora a idéia da convergência nos anos de escolaridade entre países ricos e pobres não analisa os efeitos que as distorções econômicas têm sobre a redução do custo de educação formal como um dos fatores explicativos. Por exemplo, em Restuccia e Vandenbroucke (2013b, 2013c) essa convergência é analisada pela ótica da produtividade, do progresso tecnológico e da expectativa de vida. Já em outros artigos que não analisam diretamente essa convergência de escolaridade, essas distorções são fatores explícitos no modelo (Ferreira \& Pessoa, 2003, 2007).

Com respeito a divergência do diferencial de renda per capita, a resposta pode estar em um fato até então não analisado diretamente pela literatura de crescimento econômico: a educação da primeira infância. Alguns autores consideram, além do fator quantitativo "anos de escolaridade", um fator qualitativo "gastos com educação" como um possível fator que afete o capital humano do agente (Erosa, Koreshkova \& Restuccia, 2010; Manuelli \& Seshadri, 2005; Restuccia \& Vandenbroucke, 2013a, 2013c). Entretanto esses autores desconsideram a complementariedade da formação do capital humano ao longo do ciclo de vida. Além disso, apesar desses trabalhos tentarem reviver a importância dos fatores de produção para explicar o diferencial de renda entre os países, acrescentando uma medida de qualidade da educação para a formação de capital humano, esses autores não investigam a importância dos incentivos para a educação como uma forma de aumentar o nível de capital humano e, logo, a renda dos países.

Apesar de Manuelli e Seshadri (2005) incorporarem a primeira infância na formação do capital humano, os autores consideram que o investimento na primeira infância e na educação formal são bens substitutos. Isso implica que a falta de investimento na primeira infância poderia ser compensada por um investimento posterior. Mas, estudos do desenvolvimento cognitivo infantil afirmam que o investimento na primeira infância e na educação formal são complementares para a formação do capital humano (Cunha, Heckman \& Schennach, 2010; Heckman \& Cunha, 2007).

0 presente trabalho mostra que o estimulo ao investimento em educação poderia reverter a divergência da renda per capita observada entre os países subsaarianos e europeus. Além disso, um incentivo para a educação pré-escolar tem maior efeito em termos de aumento da renda per capita que um igual estimulo para a educação formal. De forma mais específica, caso os países subsaarianos realizassem uma política de subsídio educacional igual a realizada pelos países europeus, o presente trabalho estima que $97,14 \%$ do aumento da renda per capita, devido a essa política educacional, é explicado apenas pelo subsídio para a educação pré-escolar. Um importante resultado para a implementação e revisão de políticas educacionais. ${ }^{5}$

A importância da educação pré-escolar evidenciada anteriormente também é encontrada quantitativamente neste trabalho. Em 1960 os países subsaarianos e europeus tinham em média 10\% e 47\%, respectivamente, de educação da primeira infância relativamente aos Estados Unidos. Em 2010 esse percentual passou para 36\% e 69\% para a África Subsaariana e Europa, respectivamente. Assim, apesar da evolução do investimento em educação da primeira infância, os países subsaarianos não alcançaram o resultado relativo que os países europeus tinham em 1960, representando 50 anos de atraso dos países africanos relativamente aos europeus. ${ }^{6}$

\footnotetext{
${ }^{4} \mathrm{O}$ termo distorções faz referência aos diversos fatores econômicos que alteram as escolhas dos agentes. Com respeito a educação essas distorções estão representadas pela taxação sobre a educação e sobre o trabalho.

${ }^{5}$ Esse resultado é robusto com um exercício de sensibilidade no qual se reduz a complementariedade entre os bens educacionais.

${ }^{6}$ Alguns dados mais amplos podem corroborar esses resultados. Em 2004 na África Subsaariana 70,9 milhões de crianças com menos de 5 anos, ou 61 por cento do total, estavam abaixo do potencial desenvolvimento cognitivo devido a falta de cuidados básicos. Já nos países da Europa esse percentual era de apenas 18 por cento (Grantham-McGregor et al., 2007). Além disso, observa-se um menor decrescimento da taxa de mortalidade de crianças com menos de 5 anos em países da África Subsaariana relativamente a
} 
Por fim, a importância da produtividade total dos fatores e da expectativa de vida, que são objetivos secundários do presente trabalho, também se aproximam de resultados estabelecidos pela literatura de crescimento econômico. Neste trabalho, o diferencial da produtividade total dos fatores (PTF) divergiu entre os países subsaarianos e europeus no mesmo sentido da divergência da renda per capita. A importância da PTF na composição da renda pode ser vista em vários trabalhos como em Erosa et al. (2010), Hall e Jones (1999), Klenow e Rodríguez-Clare (1997), entre outros. E com respeito a expectativa de vida, os trabalho de Ferreira e Pessoa (2003, 2007), Restuccia e Vandenbroucke (2013a, 2013c) evidenciam a relevância da expectativa de vida para a renda dos países e o investimento em educação formal. 0 resultado da expectativa de vida do presente trabalho segue a mesma direção dessa literatura: caso a expectativa de vida dos países subsaarianos fosse $10 \%$ maior que em 2010 a renda per capita aumentaria em média $5 \%$, enquanto que a educação formal e infantil aumentariam $10 \%$ e $13 \%$, respectivamente.

Dessa forma, o restante do trabalho é dividido em mais 6 partes. Nas seções 2 e 3, desenvolve-se o modelo teórico e a metodologia. Na quarta e quinta seção são apresentados os resultados e as análises quantitativas. Por fim, na seção 6 realiza-se um teste de sensibilidade do modelo e a sétima seção é dedicada à conclusão.

\section{O MODELO}

O modelo utilizado se baseia principalmente em Ferreira e Pessoa $(2003,2007)$ e Bils e Klenow (2000). Além disso, ao considerar a relevância da educação pré-escolar na formação do capital humano acrescenta-se à literatura de crescimento econômico os trabalhos de Cunha et al. (2010) e Heckman e Cunha (2007).

O modelo é de tempo contínuo. A cada momento de tempo nasce uma quantidade de agentes homogêneos. Esses agentes vivem finitos períodos e decidem o tempo que eles irão obter educação formal, a quantidade de educação pré-escolar e o consumo ao longo do ciclo de vida. 0 período em que o agente irá começar a obter escolaridade e a aposentadoria são exógenos, diferente do modelo de Ferreira e Pessoa (2007). Além disso, no período em que o agente está se educando ele não pode trabalhar. Dessa forma, como a aposentadoria é exógena, tem-se que o tempo em que o agente vai permanecer no mercado de trabalho depende negativamente do tempo que o agente irá permanecer se educando. Por simplicidade, o capital humano não dependerá da experiência no mercado de trabalho, sendo função apenas dos anos de escolaridade e da educação da primeira infância.

Existem dois setores na economia. O setor 1 produz os bens de capitais e consumo e o setor 2 produz os bens de educação. O governo tributa a educação pré-escolar e a formal, os salários dos trabalhadores e o capital físico. Com a receita da tributação, o governo faz transferências para os agentes de forma a ter equilíbrio fiscal.

\subsection{Firmas}

Existem dois setores na economia: um que produz os bens de consumo e capital e outro que produz os bens de educação. A função de produção do setor $i$ é dada pela seguinte equação:?

$$
Y_{i}=A_{i} K_{i}^{\alpha_{i}} H_{i}^{1-\alpha_{i}}
$$

em que $A_{i}$ é a produtividade total de fatores do setor $i ; K_{i}$ é o capital físico destinado ao setor $i ; H_{i}$ é o trabalho efetivo que é destinado ao setor $i$; e $\alpha_{i}$ é a elasticidade do bem $i$ com relação ao capital. 0

\footnotetext{
países da zona do Euro. De acordo com dados do Banco Mundial, em 1965 a cada mil crianças nascidas na África Subsaariana 255 morriam antes de completar 5 anos enquanto que nos países da zona do euro esse número de mortes era igual a 36 . Em 2010 esse número de mortes caiu para 105 na África Subsaariana e para 4 nos países da zona do euro. Esses fatos ajudam a entender os resultados deste trabalho, pois mostram um maior cuidado com a primeira infância nos países europeus relativamente aos países subsaarianos.

${ }^{7}$ O setor de bens de consumo e capital é representado por $i=1$ e o setor educacional por $i=2$.
} 
trabalho efetivo é função dos anos formais ${ }^{8}$ de escolaridade, $T_{s}$, do consumo de educação da primeira infância, $x$, e do trabalho destinado ao setor $i, L_{i}$. Os anos de escolaridade e o consumo de educação da primeira infância afetam o capital humano através da função $\Phi\left(T_{s}, x\right)$. Logo, tem-se

$$
H_{i}=e^{\Phi\left(T_{s}, x\right)} L_{i}
$$

em que $\Phi_{T_{s}}\left(T_{s}, x\right)>0$ e $\Phi_{x}\left(T_{s}, x\right)>0$.

Intuitivamente quanto maior for os anos de escolaridade e o consumo de educação da primeira infância maior será o trabalho efetivo.

Por simplicidade, supõe-se que existe livre mobilidade dos fatores entre o setor 1 e o setor 2 . Dessa forma, o salário, $w$, e o preço do capital, $R$, que são dados pelas condições de primeira ordem da firma, serão iguais entre os setores. Logo, sendo $q$ o preço do bem 2 dado em termos relativos ao preço do bem 1 tem-se

$$
\begin{gathered}
\alpha_{1} A_{1} \kappa_{1}^{\alpha_{1}-1}=q \alpha_{2} A_{2} \kappa_{2}^{\alpha_{2}-1}=R \\
\left(1-\alpha_{1}\right) A_{1} \kappa_{1}^{\alpha_{1}}=q\left(1-\alpha_{2}\right) A_{2} \kappa_{2}^{\alpha_{2}}=w,
\end{gathered}
$$

em que $\kappa_{i}=\frac{K_{i}}{e^{\Phi\left(T_{s}, x\right)} L_{i}}$.

Após algumas manipulações algébricas chega-se ao produto em unidades efetivas de cada setor:

$$
y_{i}(q, \tilde{\mathcal{\kappa}})=A_{i} l e^{\Phi\left(T_{s}, x\right)} \kappa_{i}(q)^{\alpha_{i}} l_{i}(q, \tilde{\mathcal{\kappa}})
$$

$\operatorname{com} \tilde{\kappa}=\frac{K_{1}+K_{2}}{e^{n t} e^{\Phi\left(T_{s}, x\right) l}}$.

Na equação (4), $l$ é o número de trabalhadores per capita e $l_{i}$ é a proporção dos trabalhadores do setor $i$ com relação ao número de trabalhadores totais da economia. Além disso, $e^{n t}$ representa a população total no tempo $t$ com $n$ representando a taxa de crescimento populacional. ${ }^{9}$

\subsection{Consumidores}

Os agentes vivem um número finito de anos dado por $T$. O ciclo de vida do agente é dividido em quatro fases: $T_{i}, T_{s}, T_{w}$ e $T_{R}$ que representam os anos da primeira infância, os anos que o agente obtêm escolaridade formal, os anos que o agente irá trabalhar e os anos de aposentadoria, respectivamente. Os agentes conhecem $T$ no momento em que nascem e a cada período de tempo eles escolhem o quanto consumir. Além disso, o indivíduo também escolhe quanto tempo ele irá adquirir de educação formal, $T_{s}$, e quanto irá consumir de educação da primeira infância, $x$. Como a aposentadoria não é decidida pelo agente tem-se que ao escolher os anos de educação formal o agente também está escolhendo indiretamente o tempo que ele vai permanecer trabalhando, $T_{w}$. Nos primeiros $T_{i}$ anos de vida o agente decide quanto irá gastar com a primeira infância e a partir dos $T_{i}$ anos de vida o agente começa a obter educação formal. $O$ agente também conhece $T_{i}$ no momento em que nasce. $O$ ganho de utilidade do agente é representado por

$$
\int_{s}^{s+T} e^{-\rho(t-s)} \cdot \frac{c(t, s)^{1-\frac{1}{\sigma}}-1}{1-\frac{1}{\sigma}} \mathrm{d} t
$$

em que $s$ representa a geração do agente, $\rho$ representa a taxa de desconto intertemporal, $c(t, s)$ é o consumo do agente da geração $s$ no tempo $t$ e $\sigma$ é o parâmetro que fornece a elasticidade de substituição intertemporal do consumo.

A restrição orçamentária do consumidor mostra a igualdade entre o valor presente do ganho do indivíduo com o valor presente da despesa. A despesa é composta pelo consumo ao longo do tempo, pelo

\footnotetext{
${ }^{8}$ Considera-se anos formais de escolaridade os anos considerados a partir da educação primária.

${ }^{9}$ Ver a seção sobre a demografia.
} 
gasto com a educação pré-escolar e pelo gasto com a educação formal. A parte da receita é composta pela renda adquirida pelo trabalho e pelas transferências do governo. Logo, a restrição orçamentária será dada por

$$
\begin{aligned}
\int_{s}^{s+T} e^{-r(t-s)} c(t, s) \mathrm{d} t+\left(1+\tau_{H_{c}}\right) \int_{s}^{s+T_{i}} & e^{-r(t-s)} x q \mathrm{~d} t+\left(1+\tau_{H}\right) \int_{s+T_{i}}^{s+T_{i}+T_{s}} e^{-r(t-s)} q \mathrm{~d} t= \\
& \left(1-\tau_{L}\right) \int_{s+T_{y}}^{s+T_{y}+T_{w}} e^{-r(t-s)} w\left(s, T_{s}, X\right) \mathrm{d} t+\int_{s}^{s+T} e^{-r(t-s)} \chi \mathrm{d} t,
\end{aligned}
$$

em que $T_{y}=T_{i}+T_{s} ; w\left(s, T_{s}, X\right)=w e^{\Phi\left(T_{s}, x\right)}$, representa o salário do coorte $s$ com $x$ unidades de consumo de educação da primeira infância e $T_{S}$ anos de escolaridade; $r$ é a taxa de juros; $\tau_{H}$ é a taxa de imposto ou subsídio cobrado sobre os bens de educação formal; $\tau_{H_{c}}$ é a taxa de imposto ou subsídio cobrado sobre a educação de primeira infância; $q$ é o custo de se adquirir educação; $\tau_{L}$ é a taxa de imposto cobrado sobre o salário; e $\chi$ é a transferência do governo.

No nível de consumo ótimo

$$
c(s, t)=c(s, s) e^{\sigma(r-\rho)(t-s)} .
$$

Logo, substituindo a equação (6) na restrição orçamentária tem-se

$$
\begin{aligned}
& c(s, s)=\frac{v_{\sigma}}{r}\left\{\left(1-\tau_{L}\right)\right. w e^{\Phi\left(T_{s}, x\right)} e^{-r T_{y}}\left(1-e^{-r T_{w}}\right)+\chi\left(1-e^{-r T}\right) \\
&\left.-\left(1+\tau_{H}\right) q e^{-r T_{i}}\left(1-e^{-r T_{s}}\right)-q x\left(1+\tau_{H_{c}}\right)\left(1-e^{-r T_{i}}\right)\right\},
\end{aligned}
$$

em que

$$
v_{\sigma}=\frac{(1-\sigma) r+\sigma \rho}{1-e^{-[(1-\sigma) r+\sigma \rho] T}} .
$$

Assim, a equação (7) diz que o consumo de cada geração no tempo inicial de vida é igual, em valor presente, a renda que o agente irá obter do trabalho mais as transferências do governo menos o gasto com educação formal e educação da primeira infância.

Além de escolher consumo, o agente também escolhe a quantidade de educação pré-escolar e o tempo em que irá permanecer adquirindo educação formal. Para tanto, o agente maximiza a renda líquida em valor presente influenciada pela educação pré-escolar, $x$, e pelos anos de escolaridade $T_{s} \cdot{ }^{10}$ Logo,

$$
\begin{aligned}
\max _{T_{s}, x}\left\{\left(1-\tau_{L}\right) \int_{s+T_{y}}^{s+T_{y}+T_{w}} e^{-r(t-s)} w\left(s, T_{s}, x\right) \mathrm{d} t-\left(1+\tau_{H}\right)\right. & \int_{s+T_{i}}^{s+T_{i}+T_{s}} e^{-r(t-s)} q \mathrm{~d} t \\
& \left.-\left(1+\tau_{H_{c}}\right) \int_{s}^{s+T_{i}} e^{-r(t-s)} x q \mathrm{~d} t\right\}
\end{aligned}
$$

Note que $T_{i}+T_{s}+T_{w}=T-T_{R}$ que não depende dos anos de escolaridade. Logo, ao supor que a função $\Phi\left(T_{s}, x\right)$ é diferenciável em ambos os argumentos, a condição de primeira ordem de (8) com respeito a $T_{S}$ será dado por

$$
\left(1-\tau_{L}\right) w e^{\Phi\left(T_{s}, x\right)} \Phi_{1}\left(T_{s}, x\right)\left(\frac{1-e^{-r T_{w}}}{r}\right)=\left(1-\tau_{L}\right) w e^{\Phi\left(T_{s}, x\right)}+\left(1+\tau_{H}\right) q
$$

e a condição de primeira ordem com respeito a $x$ será

$$
\left(1-\tau_{L}\right) w e^{\Phi\left(T_{s}, x\right)} \Phi_{2}\left(T_{s}, x\right) e^{-r\left(T_{i}+T_{s}\right)}\left(\frac{1-e^{-r T_{w}}}{r}\right)=\left(1+\tau_{H_{c}}\right) q \frac{1-e^{-r T_{i}}}{r}
$$

\footnotetext{
${ }^{10}$ Note que o agente tem preferência apenas por consumo.
} 
A equação (9) diz que, dado o gasto com a educação da primeira infância, o impacto nos ganhos do trabalho de um ano adicional de escolaridade é igual ao custo de oportunidade de ficar mais um ano sem trabalhar mais o custo financeiro de adquirir mais um ano de escolaridade. Como a educação de primeira infância afeta o salário, pode-se notar que esta educação entra em duas partes na equação: no primeiro termo do lado direito e no termo do lado esquerdo. Dessa forma , ao dividir toda a equação (9) por $e^{\Phi\left(T_{s}, x\right)}$ o capital humano irá passar a dividir o custo da educação formal. Assim, um maior investimento na educação pré-escolar irá reduzir o custo da educação formal, podendo implicar uma maior propensão a obter educação formal. Do mesmo modo, ao dividir a equação (10) por $e^{\Phi\left(T_{s}, x\right)}$ a educação formal poderá induzir, a obtenção de educação pré-escolar.

Um outro ponto importante a notar é que ao dividir a equação (9) por $\left(1-\tau_{L}\right)$ tem-se a razão $\left(1+\tau_{H}\right) /\left(1-\tau_{L}\right)$ multiplicando o custo da educação $q$. Essa razão é definida neste trabalho como as distorções econômicas sobre o custo da educação. Tais distorções afetam a escolha ótima do nível de educação. 0 mesmo argumento vale para a equação (10).

\subsection{Demografia}

A cada período de tempo nasce um montante $m e^{n t}$ de pessoas idênticas. Como a população total no período $t$ será uma soma de todas as gerações que estão vivas no período $t$, então a população total será

$$
\int_{t-T}^{t} m e^{n a} \mathrm{~d} a=m\left(\frac{1-e^{-n T}}{n}\right) e^{n t},
$$

em que $t-T$ representa a geração mais velha e $t$ a mais nova. Considerando que $m=n /\left(1-e^{-n T}\right)$ então a população total no período $t$ será $e^{n t}$ e a taxa de crescimento populacional será dada por $n$. Para uma certa geração $s \in[t-T, t]$ tem-se que a parcela da população no período $t$ dessa geração será dada por

$$
N(s, t)=\frac{m e^{n s}}{e^{n t}}=m e^{-n(t-s)} .
$$

Definindo a idade dos indivíduos da geração $s$ no tempo $t$ como $\epsilon=t-s \geq 0$ pode-se ${ }^{11}$ simplificar a equação anterior como $N(\epsilon)=m e^{-n(\epsilon)}$. Além disso, considerando que em cada período de tempo a parcela de pessoas na primeira infância, na educação formal, no mercado de trabalho e na aposentadoria sejam representadas respectivamente por $N_{i}, N_{s}, N_{w}$ e $N_{R}$,

$$
\begin{aligned}
N_{i} & =\int_{0}^{T_{i}} m e^{-n \epsilon} \mathrm{d} \epsilon=\frac{1-e^{-n T_{i}}}{1-e^{-n T}} \\
N_{s} & =\int_{T_{i}}^{T_{i}+T_{s}} m e^{-n \epsilon} \mathrm{d} \epsilon=e^{-n T_{i}} \frac{1-e^{-n T_{s}}}{1-e^{-n T}} \\
N_{w} & =\int_{T_{y}}^{T_{y}+T_{w}} m e^{-n \epsilon} \mathrm{d} \epsilon=e^{-n T_{y}} \frac{1-e^{-n T_{w}}}{1-e^{-n T}} \\
N_{R} & =\int_{T_{y}+T_{w}}^{T_{y}+T_{w}+T_{R}} m e^{-n \epsilon} \mathrm{d} \epsilon=e^{-n\left(T_{y}+T_{w}\right)} \frac{1-e^{-n T_{R}}}{1-e^{-n T} .}
\end{aligned}
$$

Note que somando as equações anteriores $N_{i}+N_{s}+N_{w}+N_{R}=1$.

\subsection{Consumo agregado}

Para obter o equilíbrio no mercado de bens dessa economia é necessário saber o consumo agregado per capita. Este é calculado ao somar os consumos de equilíbrio no período $t$ de cada geração $s$ que está

${ }^{11}$ Note que $\epsilon \in[0, T]$. 
viva em $t$ e dividir pelo tamanho da população em $t$. Como a parcela de cada coorte no período $t$ é dada por $N(\epsilon)$, então

$$
c=\frac{C(t)}{e^{n t}}=\int_{0}^{T} N(\epsilon) c(\epsilon) \mathrm{d} \epsilon .
$$

Substituindo a equação (7) na equação anterior, o consumo agregado médio será

$$
c=z m \frac{1-e^{-T(n-\sigma(r-\rho))}}{n-\sigma(r-\rho)},
$$

com

$$
\begin{aligned}
& z=\frac{(1-\sigma) r+\sigma \rho}{1-e^{-[(1-\sigma) r+\sigma \rho] T}}\left\{\left(1-\tau_{L}\right)\right. w e^{\Phi\left(T_{s}, x\right)} e^{-r T_{y}} \frac{\left(1-e^{-r T_{w}}\right)}{r}+\chi \frac{\left(1-e^{-r T}\right)}{r} \\
&\left.-\left(1+\tau_{H}\right) q e^{-r T_{i}} \frac{\left(1-e^{-r T_{s}}\right)}{r}-\left(1+\tau_{H_{c}}\right) x q \frac{\left(1-e^{-r T_{i}}\right)}{r}\right\}
\end{aligned}
$$

\subsection{Governo}

O governo transfere a receita dos impostos de forma a obter o equilíbrio fiscal. Dessa forma, a restrição orçamentária do governo será, em termos per capita, dada por

$$
\tau_{H} q N_{s}+\tau_{K} R_{1} \kappa+\tau_{H_{c}} x q N_{i}+\tau_{L} w e^{\Phi\left(T_{s}, x\right)} N_{w}=\chi,
$$

em que $N_{i}, N_{s}$ e $N_{w}$ são dadas pelas equações encontradas na demografia e $\kappa$ indica o capital per capita da economia.

A equação (16) diz que toda a transferência que o governo faz em cada momento de tempo é financiada pela arrecadação de impostos que incidem sobre o custo da educação, o capital e sobre o trabalho.

\subsection{Equilíbrio}

Em steady-state o equilíbrio será formado pelo equilíbrio no mercado de bens de educação, no mercado de bens de consumo e capital, no mercado de ativos e pelo equilíbrio da escolha educacional.

(i) Mercado de bens de educação:

$$
y_{2}(q, \tilde{\kappa})=N_{s}+x N_{i}
$$

(ii) Mercado de bens de consumo e capital:

$$
y_{1}(q, \tilde{\kappa})=c+(\delta+n) k
$$

(iii) Mercado de ativos:

$$
r=\left(1-\tau_{k}\right) R-\delta=\left(1-\tau_{k}\right) \alpha_{1} A_{1} \kappa_{1}^{\alpha_{1}-1}-\delta .
$$

(iv) A condição de equilíbrio da escolha educacional e do gasto com a primeira infância são representadas pela equação (9) e (10) depois de substituir $w$ pelo equilíbrio de oferta e de demanda por emprego.

\section{METODOLOGIA}

Começa-se a metodologia especificando a formação do capital humano dado pela função $\Phi\left(T_{s}, x\right)$. Em seguida calibra-se os parâmetros de incentivos das economias analisadas no trabalho. Para finalizar a seção, utiliza-se os incentivos calibrados para fazer a simulação do modelo e, logo, avaliar a eficiência deste em reproduzir os dados observados na realidade. 


\subsection{Capital Humano}

Psacharopoulos (1994) ao estimar o retorno minceriano da educação para diversos países estima que quanto maior o nível de escolaridade do país menor é o retorno da educação. Logo, Bils e Klenow (2000) consideram uma função para a escolaridade com retornos marginais decrescentes, diferente daquela relação linear minceriana. Entretanto essas duas especificações não consideram a primeira fase da educação como um componente da formação do capital humano. Dessa forma, acrescenta-se o trabalho de Heckman e Cunha (2007) e Heckman et al. (2010) para especificar o capital humano.

Heckman e Cunha (2007) considera que o capital humano é formado por investimentos em diferentes estágios da vida da criança. ${ }^{12}$ Considerando apenas duas fases de investimento na formação do capital humano, os autores discutem qual a especificação que descreve a evidência da literatura empírica, a qual o retorno do investimento em adolescentes desfavorecidos na infância era muito baixo, enquanto que o retorno em crianças desfavorecidas era alto. Nesse sentido, os autores propõe uma função CES para a formação do capital humano dos agentes, levando em conta essas duas fases da vida.

Dessa forma, o presente trabalho utiliza uma função CES para a formação do capital humano como em Heckman e Cunha (2007), e parâmetros $\theta$ e $\varphi$ para o retorno da educação como descrito por Bils e Klenow (2000):

$$
\Phi\left(T_{s}, x\right)=\theta \frac{\left\{\left[\gamma\left(x T_{i}\right)^{\lambda}+(1-\gamma) T_{s}^{\lambda}\right]^{\frac{1}{\lambda}}\right\}^{1-\varphi}}{1-\varphi},
$$

com $\lambda \leq 1, \gamma \in[0,1], \varphi \in[0,1]$ e $\theta \geq 0$.

Note que a elasticidade de substituição entre $x$ e $T_{S}$ é $1 /(1-\lambda)$. Além disso, a sensibilidade da produtividade marginal de um tipo de educação com respeito ao outro tipo é representado pelo sinal da seguinte derivada:

$$
\begin{aligned}
\Phi_{x T_{s}}\left(T_{s}, x\right) & =\Phi_{T_{s} x}\left(T_{s}, x\right) \\
& =\frac{T_{i}^{\lambda}(-1+\gamma) \gamma(-1+\varphi+\lambda) \theta T_{s}^{-1+\lambda} x^{-1+\lambda}\left(\left(T_{s}^{\lambda}(1-\gamma)+\left(x T_{i}\right)^{\lambda} \gamma\right)^{\frac{1}{\lambda}}\right)^{1-\varphi}}{\left((1-\gamma) T_{s}^{\lambda}+\gamma\left(x T_{i}\right)^{\lambda}\right)^{2}} .
\end{aligned}
$$

Note que para $\Phi_{T_{s} x}\left(T_{s}, x\right)>0$ é necessário que $(-1+\varphi+\lambda)<0$ uma vez que $(-1+\gamma)<0$. Como $\lambda \leq 1$ esse sinal é fortemente dependente de $\varphi$. No caso em que os bens são substitutos perfeitos tem-se $\lambda=1$ e $\gamma=1 / 2$. Logo, a derivada anterior seria negativa e o maior investimento na educação da primeira infância reduziria a produtividade marginal da educação formal. Entretanto, de acordo com Heckman e Cunha (2007) o caso de substitutos perfeitos não é sustentado pela evidência empírica.

Outro caso extremo seria o de complementos perfeitos em que a equação (20) seria

$$
\Phi\left(T_{s}, x\right)=\theta \frac{\left\{\min \left\{T_{s}, x T_{i}\right\}\right\}^{1-\varphi}}{1-\varphi} .
$$

Note que nesse caso, a escolha ótima do agente seria $T_{s}=x T_{i}$ e qualquer sobre-investimento não afetaria o capital humano.

Ao desconsiderar a educação pré-escolar no cômputo do capital humano a maioria da literatura de crescimento econômico anterior ao presente trabalho ${ }^{13}$ assumia implicitamente que os dois estágios

\footnotetext{
${ }^{12}$ Por exemplo, quando a criança ainda se encontra no útero da mãe.

${ }^{13}$ Como exemplo, Ferreira e Pessoa (2003), Ferreira e Pessoa (2007), Erosa et al. (2010), Restuccia e Vandenbroucke (2013c), Bils e Klenow (2000), entre outros. O trabalho Manuelli e Seshadri (2005) apesar de incorporar a primeira infância como formador do capital humano, o capital humano da primeira infância pode ser substituido pelo capital humano posterior a essa fase.
} 
de formação de capital humano são substitutos. Mas, de acordo com Heckman e Cunha (2007) uma alocação ótima de recursos entre as duas fases seria uma distribuição do investimento entre os dois tipos de educação, de forma a existir certo grau de complementariedade na equação (20), ou seja o parâmetro $\lambda$ seria menor que zero. Dessa forma, a equação (21) terá sinal positivo indicando que um maior investimento educacional na primeira fase da vida irá levar a uma maior contribuição da educação formal para a produtividade do trabalhador.

\subsection{Calibração}

A calibração é feita para 26 países da África subsaariana e 17 países europeus ${ }^{14}$ para os anos 1960 e 2010. Os Estados Unidos também são incluídos na calibração, pois são considerados como a economia de referência.

A estratégia de calibração é dividida em duas partes. Primeiramente, calibra-se exogenamente alguns parâmetros para a economia dos Estados Unidos. Dado os parâmetros exógenos, obtêm-se alguns parâmetros endogenamente no modelo. Na segunda parte da calibração utiliza-se os parâmetros obtidos endogenamente na economia de referência para calibrar endogenamente alguns parâmetros para os países subsaarianos e europeus.

Os parâmetros exógenos podem ser invariantes no tempo e nos países. A Tabela 1 apresenta os parâmetros invariantes entre os países e no tempo.

A taxa de crescimento populacional, $n$, é a média do crescimento populacional americano entre 1900 e 2010 obtidos no US Census; para taxa de depreciação do capital, $\delta$, usa-se a calibração de Ferreira (2013). Os parâmetros da taxa de desconto intertemporal do consumo, $\rho$, e da taxa de juros, $r$, seguem Restuccia e Vandenbroucke (2013a); os parâmetros que definem o comportamento da função CES do capital humano, $\gamma$ e $\lambda$, são estimações de Heckman et al. (2010); os parâmetros que governam o retorno educacional, $\theta$ e $\varphi$, são estimados por Bils e Klenow (2000); a elasticidade do produto do setor 1 e do

Tabela 1. Parâmetros exógenos invariantes no tempo e entre os países.

\begin{tabular}{lcl}
\hline Parâmetros & Valores & \multicolumn{1}{c}{ Origem } \\
\hline$n$ & $\log (1,0125)$ & US Census \\
$\delta$ & $\log (1,066)$ & Ferreira (2013) \\
$r$ & $\log (1,04)$ & Restuccia e Vandenbroucke (2013a) \\
$\rho$ & $\log (1,04)$ & Restuccia e Vandenbroucke (2013a) \\
$\gamma$ & $-0,781$ & Heckman et al. (2010) \\
$\lambda$ & 0,448 & Heckman et al. (2010) \\
$\theta$ & 0,32 & Bils e Klenow (2000) \\
$\varphi$ & 0,58 & Bils e Klenow (2000) \\
$\alpha_{2}$ & 0,05 & Ferreira e Pessoa (2007) \\
$\alpha_{1}$ & 0,4 & Ferreira e Pessoa (2007) \\
$T_{i}$ & 6 & Ferreira e Pessoa (2003) \\
$\sigma$ & 1 & Ferreira e Pessoa (2003) \\
\hline
\end{tabular}

\footnotetext{
${ }^{14} \mathrm{O}$ conjunto de países africanos é formado por Benin, Botswana, Burundi, Camarões, República Centro Africana, República Democrática do Congo, Costa do Marfim, Gabão, Gâmbia, Gana, Quénia, Lesoto, Malawi, Mali, Mauritânia, Ilhas Maurício, Moçambique, Namíbia, Níger, Ruanda, Senegal , África do Sul, Tanzânia, Togo, Uganda e Zâmbia. Os países europeus são Áustria, Bélgica, Chipre, Dinamarca, Finlândia, França, Grécia, Islândia, Irlanda, Itália, Holanda, Noruega, Portugal, Romênia, Espanha, Suécia e Reino Unido.
} 
produto do setor 2 com respeito ao capital, $\alpha_{1}$ e $\alpha_{2}$, foram obtidos de Ferreira e Pessoa (2007); o primeiro ciclo da vida o agente, $T_{i}$, é dada por Ferreira e Pessoa (2007) e Heckman et al. (2010); e, por fim, assumese que a elasticidade de substituição intertemporal do consumo, $\sigma$, é igual a 1 , implicando em uma forma funcional logaritmica para a função utilidade.

Neste trabalho a proporção de trabalhadores americanos no setor educacional é calibrada através do NIPA ao dividir a variável Full time equivalent employees in Educational Services pela variável Full time equivalent employees. Para o ano de 1960 encontra-se $l_{2}=0,009615$ e para 2010, $l_{2}=0,02392$. Dado $l_{2}$, calibra-se $A_{2}$ endogenamente para os Estados Unidos. Em seguida, considera-se $A_{2}$ invariante entre os países passando a encontrar $l_{2}$ endogenamente.

Cada elemento do conjunto $\left\{T, T_{s}, N_{w}, i, y\right\}$ varia para cada economia e para cada ano. A expectativa de vida, $T$, é calibrada com a variável Life expectancy at birth do World Development Indicators. Em BarroLee Educational Attainment Dataset usa-se a variável Average Years of Total Schooling of Population Aged 15 and over para os anos de escolaridade formal, $T_{s}$. As variáveis $N_{w}, i$ e $y$ são encontradas em Penn World Table Version 7.1. A proporção de trabalhadores com respeito a população total, $N_{w}$, é encontrada ao dividir a variável rgdpl2 pela variável rgdpl2wok. $O$ investimento, $i$, e a renda, $y$, são relativos a renda dos Estados Unidos. Como a variável $c i$ do PWT é o investimento relativo a renda de cada país e a variável $y$ é a renda de dado país relativa a renda dos Estados Unidos, faz-se $i=y * c i$ para ter o investimento relativo à renda dos Estados Unidos.

Uma vez que no presente trabalho só existem dois setores de produção e que os bens do setor 2 são medidos em termos dos bens do setor 1 através do preço relativo $q$, a renda de cada economia segue a seguinte forma funcional, as quais representam o equilíbrio do modelo:

$$
y=y_{1}(q, \tilde{\kappa})+q y_{2}(q, \tilde{\kappa}) .
$$

Dado a explanação anterior sobre a calibração das variáveis exógenas, agora apresenta-se a calibração endógena. A primeira parte da calibração endógena é realizada apenas para os Estados Unidos, encontrando o conjunto de parâmetros $\left\{A_{1}, A_{2}, \tau_{H}, \tau_{l}, \tau_{K}, T_{r}, k\right\} .{ }^{15} \mathrm{O}$ valor de $T_{r}$ é encontrado da equação $T_{r}=T-T_{w}-T_{s}-T_{i}$, em que $T_{w}$ soluciona a equação da proporção de trabalhadores com respeito a população total, $N_{W}$, que é apresentada na demografia do modelo. 0 capital em unidades eficientes, $k$, é dado por

$$
k=\frac{i}{\delta+n}
$$

Os outros parâmetros são encontrados conjuntamente com as variáveis $q$ e $x$ ao resolver um problema de minimização composto pela soma dos quadrados das equaçõesque representam o equilíbrio da economia: ${ }^{16}$

$$
\begin{aligned}
\min _{A_{1}, A_{2}, q, x, \tau_{L}, \tau_{K}, \tau_{H}} & \left\{\left(\frac{\left(1-\tau_{L}\right) w e^{\Phi\left(T_{s}, x\right)} \Phi_{1}\left(T_{s}, x\right)\left(\frac{1-e^{-r T_{w}}}{r}\right)}{\left(1-\tau_{L}\right) w e^{\Phi\left(T_{s}, x\right)}+\left(1+\tau_{H}\right) q}-1\right)^{2}+\left(\frac{y}{y_{1}(q, \tilde{\kappa})+q y_{2}(q, \tilde{\kappa})}-1\right)^{2}\right. \\
& +\left(\frac{\left(1-\tau_{L}\right) w e^{\Phi\left(T_{s}, x\right)} \Phi_{2}\left(T_{s}, x\right) e^{-r\left(T_{i}+T_{s}\right)}\left(\frac{1-e^{-r T_{w}}}{r}\right)}{\left(1+\tau_{H_{c}}\right) q\left(\frac{1-e^{-r T_{i}}}{r}\right)}-1\right)^{2}+\left(\frac{y_{2}(q, \tilde{\kappa})}{N_{s}+x N_{i}}-1\right)^{2} \\
& \left.+\left(\frac{y_{1}(q, \tilde{\kappa})}{c+(\delta+n) k}-1\right)^{2}+\left(\frac{r+\delta}{\left(1-\tau_{k}\right) \alpha_{1} A_{1} \kappa_{1}^{\alpha_{1}-1}}-1\right)^{2}+\left(\frac{l_{i}(\tilde{\kappa}, q)}{\frac{\tilde{\kappa}-\kappa_{j}(q)}{\kappa_{i}(q)-\kappa_{j}(q)}}-1\right)^{2}\right\}
\end{aligned}
$$

\footnotetext{
${ }^{15}$ Aqui considera-se que $\tau_{H_{c}}=\tau_{H}$. Na seção dos contrafactuais esta hipótese é relaxada.

${ }^{16}$ Restuccia e Vandenbroucke (2013b, 2013c) utilizam um método semelhante a este.
} 
A segunda parte da calibração endógena é realizada para os países europeus e subsaarianos. Para tanto, usa-se o valor de $A_{2}$ encontrado para os Estados Unidos e estima-se o conjunto de parâmetros $\left\{A_{1}, l_{2}, q, x, \tau_{H}, \tau_{K}, \tau_{L}, T_{r}\right\}$ pelo mesmo procedimento descrito no parágrafo anterior.

\subsection{Simulação}

Para a simulação são considerados os parâmetros obtidos na seção anterior $\left\{A_{1}, A_{2}, \tau_{K}, \tau_{H}, \tau_{L}, T_{r}\right\}$ para obter as variáveis endógenas ao modelo $\left\{\kappa_{1}, \kappa_{2}, T_{s}, x, l_{2}, q, y\right\}$. Nesse sentido, pela equação de equilíbrio do mercado de ativos, (19), encontra-se o valor de $\kappa_{1}$. Logo, dividindo a equação (2) pela equação (3) o $\kappa_{2}$ é encontrado. Com os valores de $\kappa_{1}$ e $\kappa_{2}$, resolve-se a escolha do investimento educacional do agente ao solucionar simultaneamente as equações (9) e (10) para $T_{s}$ e $x$. 0 valor de $l_{2}$ é facilmente calculado ao resolver a equação (17). Em seguida, estima-se $q$ pela equação (3) e, por fim, $y$ através da equação (22).

A Tabela 2 mostra a diferença, média, entre demanda e oferta do setor 1 e também mostra a eficiência do modelo em reproduzir os dados observados na realidade. Como os valores das variáveis endógenas não são exatamente os valores que foram observados na realidade tem-se que a diferença entre oferta e a demanda dos bens de consumo e capital não são exatamente iguais. Mas, essa diferença é próxima de zero como pode ser observado na Tabela 2.

De acordo com a Tabela 2, o modelo reproduz, em média, exatamente os anos de escolaridade observados nos países subsaarianos tanto para o ano de 1960 quanto para 2010. Já para os países europeus, o modelo captura em média 99,9\% e 99,7\% dos anos de escolaridade observados para o ano de 1960 e 2010, respectivamente. Com respeito ao produto da economia, o ajuste médio para os países subsaarianos é de $100,7 \%$ e 100,4\% para 1960 e 2010, nessa ordem. Para os países europeus esse ajuste médio é de $98,7 \%$ e $97,9 \%$ para os anos de 1960 e 2010, respectivamente. A tabela também mostra que o valor da função objetivo da calibração (resíduo da calibração) e o resíduo da calibração equação (18) ficaram próximos de zero, reforçando a robustez do modelo. Note também que o desvio padrão é baixo para todas as entradas da Tabela 2.

\section{RESULTADOS}

A primeira parte desta seção é dedicada à apresentação dos resultados da calibração descrita na seção 3. A segunda parte é destinada aos resultados da simulação.

Tabela 2. Ajuste do modelo aos dados - Valores médios *

\begin{tabular}{lcccc}
\hline & \multicolumn{2}{c}{1960} & \multicolumn{2}{c}{2010} \\
\cline { 2 - 5 } & Europa & África & Europa & África \\
\hline$T_{S}$ calculado / $T_{S}$ observado & 0,999 & 1,000 & 0,997 & 1,000 \\
& {$[0,003]$} & {$[0,000]$} & {$[0,004]$} & {$[0,000]$} \\
$y$ calculado / $y$ observado & 0,987 & 1,007 & 0,979 & 1,004 \\
& {$[0,016]$} & {$[0,014]$} & {$[0,016]$} & {$[0,016]$} \\
Resíduo da calibração & 0,003 & 0,0002 & 0,003 & 0,0001 \\
& {$[0,0019]$} & {$[0,0001]$} & {$[0,0019]$} & {$[0,0001]$} \\
Resíduo da equação (18) & $-0,043$ & $-0,007$ & $-0,044$ & $-0,007$ \\
& {$[0,02]$} & {$[0,01]$} & {$[0,01]$} & {$[0,01]$} \\
\hline
\end{tabular}

Nota: O desvio-padrão entre colchetes. 


\subsection{Resultados da calibração}

Os parâmetros calibrados no modelo parecem estar em conformidade com o comportamento dos dados ao longo do tempo, como será apresentado ao longo desta seção.

Existe uma literatura que considera que a produtividade total dos fatores é uma importante explicação para o crescimento dos países (Erosa et al., 2010; Hall \& Jones, 1999; Klenow \& Rodríguez-Clare, 1997). O modelo deste trabalho também captou esse fato. Além disso, o subsídio para à escolha educacional também corrobora a evolução dos anos de escolaridade observada nos dados. A Tabela 3 representa o panorama geral dos resultados da calibração.

A Tabela 3 apresenta os valores médios da calibração por grupo de países para 1960 e 2010. O primeiro parâmetro a ser considerado é a produtividade total dos fatores, relativo aos Estados Unidos, do setor de bens de consumo e capital, $A_{1}$. Como mostra a tabela, entre os anos de 1960 e 2010 a produtividade total do fatores do setor 1 para os países europeus passou de $73 \%$ em 1960 para $97 \%$ em 2010 , enquanto que para os países subsaarianos esse percentual foi de $48 \%$ para $29 \%$. Logo, enquanto os países europeus reduziram em aproximadamente $24 \%$ a diferença com os Estados Unidos, os países subsaarianos aumentaram em aproximadamente 19\% essa diferença com os Estados Unidos.

A Figura 1 ajuda a observar a relação entre a produtividade total de fatores do setor 1 e a renda por trabalhador dos países.

O eixo vertical do gráfico indica a razão entre a renda por trabalhador de 2010 e a renda de 1960 , enquanto que o eixo horizontal mostra a razão entre a produtividade total dos fatores de $2010 \mathrm{com}$ respeito a 1960. Logo, os pontos do eixo horizontal que são maiores que 1, indicam que houve um aumento da produtividade total dos fatores entre 2010 e 1960 e os pontos do eixo vertical maiores que 1 indicam que ocorreu um aumento da renda per capita entre 2010 e 1960 . Nesse sentido, pode-se observar uma relação positiva entre o aumento da produtividade total dos fatores e da renda por trabalhador. Um fato interessante de se observar é que a maioria dos países europeus estão no primeiro quadrante do gráfico - que representa um aumento da PTF e da renda por trabalhador entre 2010 e 1960 — enquanto que a maioria dos países subsaarianos estão no terceiro quadrante - que indica uma redução da PTF e da renda por trabalhador entre 2010 e 1960 . Este resultado indica que, no presente modelo, a produtividade total dos fatores foi uma das causas da divergência da renda por trabalhador entre os países subsaarianos e os europeus.

O segundo parâmetro da Tabela 3 é a razão entre o subsídio educacional e o efeito líquido da taxação sobre o trabalho, ou seja essa razão representa as distorções econômicas sobre o custo da educação. ${ }^{17}$ De acordo com a tabela, em 1960 os países europeus tinham menos distorções, 31,44, para obter educação que os países subsaarianos, 40,77. Para 2010, houve uma redução das distorções educacionais para

Tabela 3. Valores médios da calibração por grupos de países

\begin{tabular}{cccccccc}
\hline & \multicolumn{3}{c}{1960} & & \multicolumn{3}{c}{2010} \\
\cline { 2 - 5 } \cline { 6 - 8 } & $A_{1}{ }^{*}$ & $\frac{\left(1+\tau_{H}\right)}{\left(1-\tau_{L}\right)}$ & $\left(1-\tau_{K}\right)^{*}$ & & $A_{1}{ }^{*}$ & $\frac{\left(1+\tau_{H}\right)}{\left(1-\tau_{L}\right)}$ & $\left(1-\tau_{K}\right)^{*}$ \\
\hline \multirow{2}{*}{ Europa } & 0,73 & 31,44 & 1,57 & & 0,97 & 8,98 & 1,11 \\
& {$[0,24]$} & {$[6,71]$} & {$[0,37]$} & & {$[0,16]$} & {$[2,07]$} & {$[0,18]$} \\
África & 0,48 & 40,77 & 1,18 & & 0,29 & 6,98 & 1,28 \\
& {$[0,19]$} & {$[14,86]$} & {$[1,04]$} & & {$[0,13]$} & {$[2,13]$} & {$[0,58]$} \\
\hline
\end{tabular}

Notas: Desvio-padrão entre colchetes. ${ }^{*}$ Valores relativos aos Estados Unidos.

\footnotetext{
${ }^{17}$ As equações (9) e (10) mostram como essa razão afeta diretamente o custo educacional.
} 
Figura 1. Relação entre a produtividade total dos fatores do setor 1 e a renda por trabalhador relativo aos Estados Unidos.

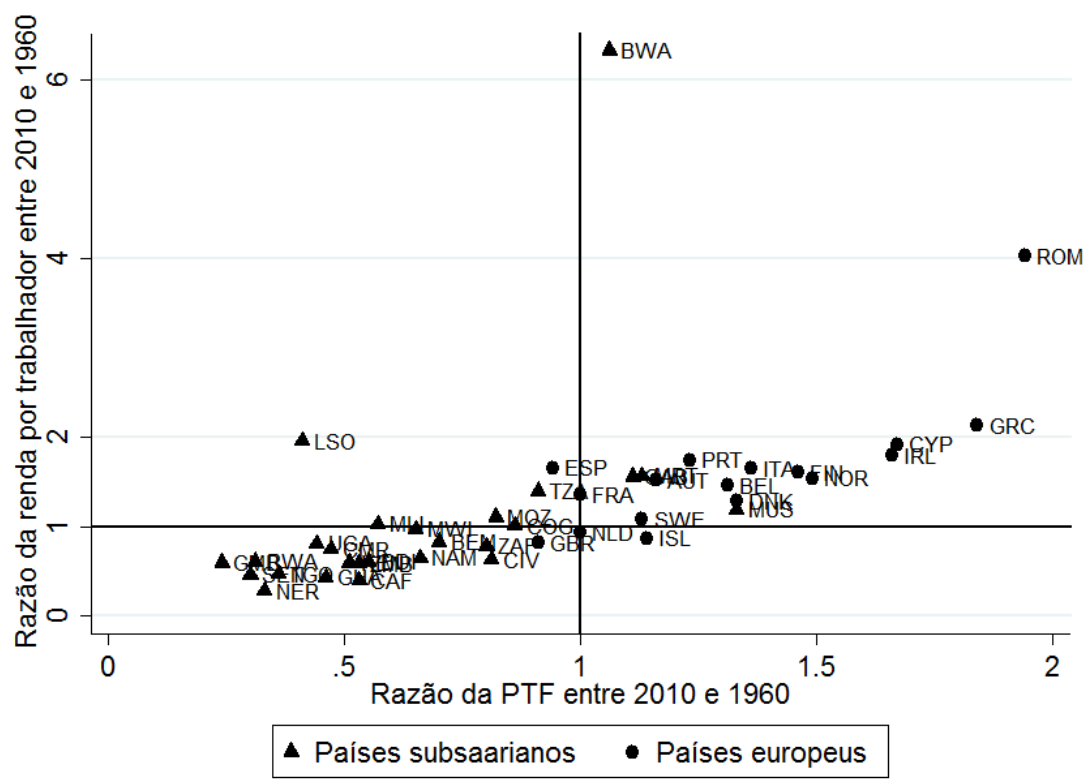

ambos os países: a distorção média dos países subsaarianos reduziu em $83 \%$ enquanto que para os países europeus essa redução foi de aproximadamente $71 \%$ entre os anos. Dessa forma, entre 1960 e 2010 os países subsaarianos reduziram relativamente mais as distorções sobre o custo da educação que os países europeus, o que ajuda a entender a convergência dos anos de escolaridade entre os dois grupos de países.

Com respeito ao imposto sobre o capital, a Tabela 3 mostra um aumento desse imposto ao longo do tempo para os países europeus, enquanto que nos países subsaarianos observa-se uma redução dessa alíquota. No presente trabalho, esse aumento da taxação sobre o capital nos países europeus é um reflexo do aumento do subsídio sobre a educação, ou seja, o maior incentivo à educação dado pelos países europeus foi financiado por um maior imposto sobre o capital.

Alguns países africanos subsidiaram o capital em 1960 ou em $2010 .{ }^{18}$ Logo, quando os países que subsidiaram o capital em algum desses anos são excluídos da amostra, os valores médios de $\tau_{K}$ para 1960 e 2010 são 0,79 e 1,04, nessa ordem. Com essa nova amostra, os países subsaarianos reduziram ao longo do tempo o incentivo para a acumulação de capital e, além disso, em ambos os anos os países subsaarianos passaram a incentivar menos a acumulação de capital que o países europeus.

\subsection{Resultados da simulação}

Agora são apresentados os resultados da simulação do modelo dado os parâmetros calibrados anteriormente. A Tabela 4 informa os valores médios relativos aos Estados Unidos da educação pré-escolar, $x$, preço da educação, $q$, proporção de trabalhadores no setor $1, l_{1}$, e do capital em unidades eficiente dos setores 1 e $2, \kappa_{1}$ e $\kappa_{2}$.

\footnotetext{
${ }^{18}$ República do Congo, Gabão, Gana e Mauricías subsidiaram o capital em 1960. O $\tau_{k}$ para esses países era igual a $-0,99,-0,84$, $-0,17$ e $-0,73$, respectivamente. Para 2010, os países Botswana, República do Congo, Lesoto, Malawi e Namíbia tiveram um valor de $\tau_{K}$ igual a $-0,73,-0,28,-0,09,-0,39$ e $-0,11$, respectivamente.
} 
Tabela 4. Valores médios da simulação por grupo de países. ${ }^{*}$

\begin{tabular}{|c|c|c|c|c|c|c|c|c|c|c|}
\hline & \multicolumn{5}{|c|}{1960} & \multicolumn{5}{|c|}{2010} \\
\hline & $x$ & $q$ & $l_{1}$ & $\kappa_{1}$ & $\kappa_{2}$ & $x$ & $q$ & $l_{1}$ & $\kappa_{1}$ & $\kappa_{2}$ \\
\hline \multirow[t]{2}{*}{ Europa } & 0,47 & 0,88 & 1,00 & 1,37 & 1,37 & 0,69 & 1,00 & 1,00 & 1,12 & 1,12 \\
\hline & {$[0,18]$} & {$[0,36]$} & {$[0,001]$} & {$[0,564]$} & {$[0,564]$} & {$[0,10]$} & {$[0,24]$} & {$[0,003]$} & {$[0,34]$} & {$[0,34]$} \\
\hline \multirow[t]{2}{*}{ África } & 0,10 & 0,30 & 1,00 & 0,46 & 0,46 & 0,37 & 0,17 & 0,99 & 0,23 & 0,23 \\
\hline & {$[0,12]$} & {$[0,21]$} & {$[0,003]$} & {$[0,76]$} & {$[0,76]$} & {$[0,21]$} & {$[0,15]$} & {$[0,01]$} & {$[0,25]$} & {$[0,25]$} \\
\hline
\end{tabular}

Notas: Desvio-padrão entre colchetes. ${ }^{*}$ Valores relativos aos Estados Unidos.

A educação pré-escolar média mostrada na Tabela 4 apresentou uma evolução tanto para os países africanos quanto para os europeus. Apesar de haver um aumento relativo maior para os países subsaarianos vale notar que em 2010 a educação pré-escolar para os países africanos era, em média, 63\% abaixo do país de referência, mas em 1960 os países europeus tinham 53\% a menos que o país de referência. Logo, em 2010 os países subsaarianos ainda não tinham atingido a educação pré-escolar relativa de 1960 dos países europeus, indicando um atraso de 50 anos com respeito à educação pré-escolar européia.

$\mathrm{O}$ aumento da distância em termos de renda per capita dos países subsaarianos e europeus não ocorreu para todos os países subsaarianos da amostra. Os países subsaarianos que se aproximaram da renda per capita média dos países europeus foram: Botswana, Lesoto, Mauritânia e Ilhas Maurício. Para esses países a educação pré-escolar relativo aos Estados Unidos para 2010 foi 0,81, 0,55, 0,31 e 0,49. Logo, apenas Mauritânia obteve educação pré-escolar abaixo da média dos países subsaarianos. Como esses países elevaram os anos de escolaridade, esse resultado fortalece a estruturação do capital humano como importante fator para entender o diferencial de renda per capita através da complementariedade entre a educação formal e infantil.

O resultado expressivo da educação pré-escolar para Botswana e Lesoto pode ser entendido pelo aumento do investimento em ambos os países ${ }^{19}$ impulsionando o aumento do benefício marginal da educação pré-escolar através do aumento do salário de equilíbrio. Além disso, o custo marginal também se reduziu entre os anos, pois o incentivo para a educação pré-escolar ponderado pelo desincentivo ao salário caiu em aproximadamente $88 \%$ e $82 \%$ para Botswana e Lesoto, respectivamente. ${ }^{20}$

Com respeito ao preço da educação, $q$, note que enquanto os países subsaarianos reduziram relativamente $q$ entre 1960 e 2010 , os países europeus se aproximaram mais da economia de referência. A equação (3) ajuda a entender. Em equilíbrio, o preço da educação se ajusta a diferença da produtividade marginal do trabalhador entre o setor 1 e o setor 2. Dessa forma, como a PTF dos países subsaarianos reduziu ao longo do tempo o preço relativo da educação também reduziu de forma a manter a igualdade entre os salários, dado pela hipótese de livre mobilidade de mão de obra entre os setores. Da mesma forma, a PTF dos países europeus aumentou entre 1960 e 2010 o que ajuda a entender esse aumento do preço relativo da educação.

A proporção relativa de trabalhadores no setor 1 não se alterou para os países europeus. Enquanto que os países subsaarianos apresentaram uma pequena redução dessa proporção relativamente a economia de referência. Essa redução implica um aumento na proporção dos trabalhadores no setor educacional. Isto pode ser explicado pela maior oferta de vagas no setor educacional, como visto em Majgaard e

\footnotetext{
${ }^{19} \mathrm{O}$ investimento relativo ao produto per capita para Botswana e Lesotho em 1960 era 0,15 e 0,02 e para 2010 esse investimento aumentou para 0,5 e 0,31, respectivamente. Logo, o estoque de capital em unidade eficientes também aumentou.

${ }^{20}$ Vale dizer que apesar desses países apresentarem uma baixa expectativa de vida acompanhada de um aumento dos anos de escolaridade, este efeito não reduziu a extensão da vida laboral do agente pois o tempo de aposentadoria se ajustou, cancelando estes efeitos.
} 
Mingat (2012). Além disso, a equação (4) diz que este aumento de $l_{2}$ afeta diretamente a quantidade per capita ofertada de bens educacionais, corroborando a evolução dos anos de escolaridade e da educação da primeira infância.

As duas últimas variáveis da Tabela 4 são o capital em unidades eficiente do setor $1 \mathrm{e} 2, \kappa_{1}$ e $\kappa_{2}$. Assim, o capital em unidades eficientes relativo a economia de referência é igual para ambos os setores. A explicação está nas condições de primeira ordem da firma. Como os termos $\alpha_{1}, \alpha_{2}$ e $A_{2}$ são constantes entre os países, o capital em unidades eficientes relativo aos Estados Unidos depende das mesmas variáveis que são constantes com respeito aos setores.$^{21}$ Dessa forma, apesar de $\kappa_{i}$ cair ao longo do tempo em ambos os grupos de países, os valores dos países subsaarianos em 2010 ainda foram muito abaixo dos países europeus: em 2010 os países europeus possuíam aproximadamente $80 \%$ a mais de $\kappa_{i}$ que os subsaarianos.

\section{ANÁLISE QUANTITATIVA}

Nesta etapa, realizam-se dois tipos de análises: uma envolvendo os subsídios educacionais e outra envolvendo a expectativa de vida e a PTF.

A análise envolvendo os subsídios educacionais seguem a sistemática de igualar os incentivos médios de 2010 dos países subsaarianos aos dos países europeus. O intuito dessas análises é observar como os países subsaarianos estariam caso adotassem uma política de incentivos econômicos similar aos subsídios europeus. Com respeito aos incentivos educacionais, realiza-se as seguinte políticas: tanto o subsídio para a educação formal quanto o subsídio para a educação pré-escolar dos países subsaarianos são igualados aos subsídios educacionais dos países europeus, $\tau_{H}=\tau_{H_{c}}=\tau_{H}^{\text {Europa }}$; iguala-se apenas o subsídio para a educação formal, $\tau_{H}=\tau_{H}^{\text {Europa }}$, e apenas para a educação pré-escolar, $\tau_{H_{c}}=\tau_{H}^{\text {Europa }}$.

Além dessas políticas educacionais, o presente trabalho também analisa o efeito sobre a educação e a renda per capita dos países subsaarianos no caso em que ocorre um aumento de $10 \%$ na expectativa de vida e no caso de um aumento de $10 \%$ na PTF.

\subsection{Políticas educacionais}

A Tabela 5 é uma resposta para pergunta: "Como evoluiria a renda e a educação dos países africanos caso as políticas africanas para a educação fossem as mesmas da média dos países europeus?" Para melhor representar esse contrafactual, os resultados da Tabela 5 estão em termos relativos dos resultados simulados para os países africanos em 2010. Além disso, também são as apresentadas três políticas educionais descritas anteriormente.

Com o subsídio educacional africano igual ao subsídio europeu para educação pré-escolar, $x$, e a formal, $T_{s}$, o grupo de países africanos aumentariam a educação formal em média 2,19 vezes enquanto que para a educação pré-escolar esse aumento seria de 10,77 vezes. Logo, essa política educacional têm maior impacto sobre a educação pré-escolar do que sobre a educação formal. Esse resultado pode ser entendido pela equação (9). O primeiro termo do lado direito dessa equação diz que quanto maior o nível educacional do agente maior é o custo de oportunidade de passar um ano a mais na escola. ${ }^{22}$ Além disso, como as duas fases educacionais são complementares na formação do capital humano o aumento da educação pré-escolar implica em um maior custo de oportunidade para cada ano adicional de educação formal. Já para a educação pré-escolar, a equação (10) diz que o indivíduo não enfrenta esse custo de oportunidade, pois o agente escolhe intensivamente a quantidade de educação na primeira fase da vida. Assim, o custo marginal de adquirir educação formal é crescente com a educação enquanto que

\footnotetext{
${ }^{21}$ Note que $\frac{\kappa_{i}}{\kappa_{i}^{\mathrm{US}}}=\left(\frac{q A_{1}}{q^{\mathrm{US}} A_{1}^{\mathrm{US}}}\right)^{\frac{1}{\alpha_{2}-\alpha_{1}}}$. Logo, $\frac{\kappa_{1}}{\kappa_{1}^{\mathrm{US}}}=\frac{\kappa_{2}}{\kappa_{2}^{\mathrm{US}}}$.

${ }^{22}$ Lembrando que no modelo o agente não pode trabalhar enquanto estiver adquirindo educação.
} 
Tabela 5. Políticas educacionais para os países subsaarianos.

\begin{tabular}{cccc}
\hline & \multicolumn{3}{c}{$\begin{array}{c}\text { Valores médios relativos } \\
\text { à simulação de } 2010\end{array}$} \\
\cline { 2 - 4 } Políticas & $y$ & $x$ & $T_{s}$ \\
\hline$\tau_{H}=\tau_{H_{c}}=\tau_{H}^{\text {Europa }}$ & 1,72 & 10,77 & 2,19 \\
& {$[0,58]$} & {$[7,56]$} & {$[1,10]$} \\
$\tau_{H}=\tau_{H}^{\text {Europa }}$ & 1,09 & 1,23 & 1,32 \\
& {$[0,08]$} & {$[0,22]$} & {$[0,32]$} \\
$\tau_{H_{c}}=\tau_{H}^{\text {Europa }}$ & 1,67 & 9,83 & 1,98 \\
& {$[0,53]$} & {$[6,58]$} & {$[0,84]$} \\
\hline
\end{tabular}

Nota: Desvio-padrão entre colchetes.

o custo marginal de adquirir educação pré-escolar é constante, explicando o resultado educacional do igual subsídio para ambas as educações.

Como era esperado, as outras duas políticas tiveram um impacto menor sobre a educação. Mas, algo interessante de se notar é que o subsídio para a educação pré-escolar tem um maior impacto sobre a educação do que o mesmo subsídio para a educação formal. De acordo com a tabela, a política para a educação pré-escolar alcança aproximadamente $91,27 \%$ e $90,41 \%$ do resultado da política simultânea para a educação pré-escolar e para a educação formal, nessa ordem. Enquanto que a política para educação formal foi responsável por aproximadamente $11,42 \%$ da evolução da educação pré-escolar e $60,27 \%$ da evolução da educação formal da política com ambos os subsídios educacionais. Note que apesar de aumentar o incentivo apenas para um dos tipos de educação o outro tipo também sofre um efeito positivo. A razão está na função de formação do capital humano em que $x$ e $T_{S}$ são bens complementares. Além disso, como o equilíbrio do modelo está em estado estacionário esses resultado estão implicitamente sustentados por políticas governamentais que são anunciadas antes de sua implementação. Logo, ao antecipar o incentivo que o governo dará na educação formal o agente já reage a esse incentivo alterando sua escolha de educação pré-escolar. Note também que se os bens educacionais fossem substitutos na formação do capital humano o agente escolheria otimamente um menor nível de educação pré-escolar como resposta a um aumento do incentivo para a educação formal.

0 efeito dos incentivos educacionais sobre a renda per capita, $y$, segue o mesmo sentido do efeito sobre a educação. Dessa forma, um maior incentivo para a aquisição de educação levaria a um aumento da renda per capita de $72 \%$, 9\% e $67 \%$ de acordo com a política de subsídio para ambas as educações, apenas para a educação formal e apenas para a educação infanil, respectivamente.

Como discutido anteriormente, o incentivo para a educação pré-escolar é o maior responsável pelo resultado educacional do primeiro política. Isso também se reflete na renda per capita: a política de incentivo para a educação pré-escolar é responsável por 97,09\% do aumento da renda per capita ocasionado pela política que incentiva a primeira e a segunda fase educacional.

Dessa forma, a educação pré-escolar parece ser um importante meio para aumentar a renda per capita dos países subsaarianos e, logo, reverter a divergência em termos de renda per capita observada entre os países subsaarianos e europeus. Esse resultado continua válido mesmo quando a complementariedade entre os bens educacionais é reduzida. Na seção 6 (sensibilidade do modelo) apresenta-se essa análise de robustez. 


\subsection{Expectativa de Vida e Produtividade Total dos Fatores}

A expectativa de vida e a produtividade total dos fatores são importantes aspectos econômicos na determinação dos diferenciais de renda per capita dos países. Nesse sentido, essa seção avalia o que ocorreria com a educação e a renda per capita dos países subsaarianos no caso que houvesse um aumento de $10 \%$ na expectativa de vida e no caso que houvesse um aumento de $10 \%$ na produtividade total dos fatores. A Tabela 6 apresenta os resultados desses aumentos.

A primeira linha da Tabela 6 mostra o que ocorreria com os países subsaarianos em 2010 caso a expetativa de vida fosse $10 \%$ maior que a de 2010 . Como esperado, todos os países subsaarianos apresentariam um aumento da sua renda per capita, ${ }^{23}$ sendo que em média a renda per capita dos países subsaarianos aumentaria em aproximadamente $5 \%$. Uma vez que a expectativa de vida não afeta diretamente a renda per capita dos países como mostra a equação (22), esse resultado é explicado pelo efeito que a expectativa de vida tem sobre a educação. Em média, os anos de escolaridade aumentariam em $10 \%$ enquanto que a educação pré-escolar aumentaria $13 \%$, ou seja, a educação aumentaria mais que proporcionalmente ao aumento da expectativa de vida. Assim, a expectativa de vida é um importante canal para políticas públicas que tenham como objetivo impactar a educação e, logo, a renda per capita.

De acordo com a Tabela 6 os países subsaarianos teriam um forte aumento da renda per capita relativa a simulação de 2010 caso a PTF fosse $10 \%$ maior que em 2010. Em média esses países aumentariam em $18 \%$ a sua renda per capita em comparação com a simulação de 2010 . Com respeito a educação, observase que esse aumennto da PTF levaria a um aumento médio de 1\% para ambas as educações.

A importância da PTF na determinação da renda é motivada pelos seus efeitos diretos e indiretos em estado estacionário sobre a renda per capita. Indiretamente, $A_{1}$ afeta o capital em unidades eficientes do setor 1 e do setor 2 e afeta o nível de capital humano através do impacto indireto sobre a educação. ${ }^{24}$ Assim , o aumento da acumulação de fatores amplifica o efeito da PTF sobre a renda dos países. Isso explica o alto impacto da PTF na renda per capita dos países subsaarianos.

\section{SENSIBILIDADE DO MODELO}

Para testar a sensibilidade do resultado da política educacional descrita anteriormente, relaxa-se a complementariedade da função de formação de capital humano de modo a manter uma elasticidade de

Tabela 6. Análise quantitativa para os países subsaarianos — Expectativa de Vida e PTF.

\begin{tabular}{lccc}
\hline & \multicolumn{3}{c}{$\begin{array}{c}\text { Valores médios relativos } \\
\text { à simulação de } 2010\end{array}$} \\
\cline { 2 - 4 } Políticas & $y$ & $x$ & $T_{s}$ \\
\hline Aumento de $10 \%$ em $T$ & 1,05 & 1,13 & 1,10 \\
& {$[0,005]$} & {$[0,014]$} & {$[0,017]$} \\
Aumento de $10 \%$ em $A_{1}$ & 1,18 & 1,01 & 1,01 \\
& {$[0,001]$} & {$[0,002]$} & {$[0,003]$} \\
\hline
\end{tabular}

Nota: Desvio-padrão entre colchetes.

\footnotetext{
${ }^{23}$ Ver a Tabela A-8 no Apêndice A (página 211).

${ }^{24}$ Com respeito ao capital, a equação (19) mostra o efeito de $A_{1}$ sobre o capital no setor 1 e a razão entre a equação (2) e (3) informa que o capital no setor 1 impacta positivamente o capital no setor 2. Logo, pela equação (3) pode-se notar que o salário de estado estacionário sem levar em conta a produtividade do trabalhador também irá aumentar. Então, o benefício marginal de adquirir uma unidade a mais de educação aumenta, levando a um aumento de $x$ e $T_{S}$ para que as equações (9) e (10) continuem sendo satisfeitas.
} 
substituição menor do que 1 . O exercício é exatamente como antes: iguala-se o subsídio educacional subsaariano ao subsídio europeu. A Figura 2 mostra este resultado de sensibilidade.

O eixo vertical da Figura 2 mostra a razão do aumento médio da renda per capita entre o subsídio educacional para apenas uma educação e o subsídio para ambas as educações africanas. Quando o valor do eixo vertical é igual a 1 isto significa que o aumento da renda per capita ocasionado por um estimulo a apenas uma fase educacional é igual ao aumento da renda per capita com o mesmo estimulo para ambas as fases educacionais. ${ }^{25} \mathrm{O}$ eixo horizontal se refere a redução do parâmetro de complementariedade da formação de capital humano dado pela equação (20). A linha com pontos em círculos representa a política relativa da educação pré-escolar e a linha pontilhada representa a política relativa para a educação formal. Dessa forma, conforme se reduz a complementariedade entre as educações a importância relativa da política para a educação pré-escolar se mantem enquanto que a política para a educação formal se torna cada vez menos importante em termos de impacto sobre a renda per capita.

Portanto, o principal resultado deste trabalho não é sensível com respeito a escolha de uma complementariedade mais fraca do que a estimada por Heckman et al. (2010).

\section{CONCLUSÃO}

O objetivo deste trabalho foi estimar, através de um modelo de equilíbrio geral, a educação préescolar de países da África Subsaariana e de países da Europa para os anos de 1960 e 2010. Logo, este artigo pôde analisar pela ótica da educação pré-escolar a divergência da renda per capita e a convergência dos anos de escolaridade entre os países da África Subsaariana e os países europeus entre 1960 e 2010. De acordo com os resultados, apesar da educação pré-escolar para os países subsaarianos ter evoluído entre 1960 e 2010 os países subsaarianos em 2010 não alcançaram a educação pré-escolar dos europeus em 1960, ou seja, os países subsaarianos estão mais de 50 anos atrasados em termos de educação pré-escolar comparativamente aos países europeus. Além disso, a produtividade total dos fatores e a expectativa de

Figura 2. SENSIBLLIDADE DO MODELO

Proporção do aumento da renda per capita capturado por cada incentivo educacional conforme a redução da complementariedade.

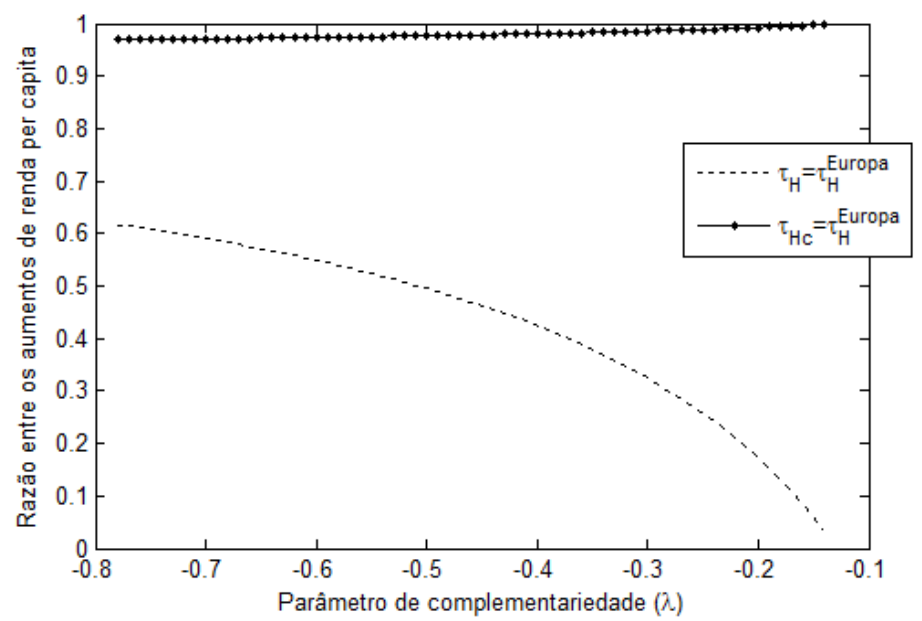

\footnotetext{
${ }^{25}$ Vale dizer que apesar de parecer graficamente que o subsídio para a educação pré-escolar tenha exatamente o mesmo efeito que o subsídio para ambas as educações quando a complementariedade é baixa, o maior valor observado dessa proporção é de 0,9985 .
} 
vida foram fatores importantes para compreender esse aumento da distância da renda per capita entre os países subsaarianos e os europeus.

Os resultados deste trabalho também sugerem que a convergência nos anos de escolaridade entre esses grupos de países pode ser explicada pelo aumento dos incentivos educacionais levando a uma redução dos custos de obter educação. Essa redução do custo está relacionada com o aumento da oferta de bens educacionais observada para os países subsaarianos.

O principal resultado deste trabalho é que um subsídio para a educação pré-escolar dos países da África subsaariana representaria mais de $97 \%$ do aumento da renda per capita de um igual subsídio tanto para a educação pré-escolar quanto para a educação formal. Este resultado mostra a importância da educação da primeira infância para políticas educacionais e, além disso, sugere que o desincentivo para a educação pré-escolar dos países subsaarianos relativo aos europeus ajuda a entender a divergência da renda per capita entre estes.

\section{REFERÊNCIAS BIBLIOGRÁFICAS}

Bils, M., \& Klenow, P.J. (2000, December). Does schooling cause growth? American Economic Review, 90(5), 1160-1183. doi: 10.1257/aer.90.5.1160

Cunha, F., Heckman, J.J. \& Schennach, S. M. (2010). Estimating the technology of cognitive and noncognitive skill formation. Econometrica, 78(3), 883-931. doi: 10.3982/ECTA6551

Erosa, A., Koreshkova, T. \& Restuccia, D. (2010). How important is human capital? A quantitative theory assessment of world income inequality. Review of Economic Studies, 77(4), 1421-1449. doi: 10.1111/j.1467937X.2010.00610.X

Ferreira, P. C. G. (2013). AIDS, longevity and long-run income. Applied Economics, 45(15), 2117-2125. doi: $10.1080 / 00036846.2012 .654915$

Ferreira, P. C. G., \& Pessoa, S. d. A. (2003, Jan). The costs of education, longevity and the poverty of nations (Ensaios Economicos $N^{0} 472$ ). Escola de Pós-Graduação em Economia da Fundação Getulio Vargas. Disponível em: http://bibliotecadigital.fgv.br/dspace/handle/10438/507

Ferreira, P. C. G., \& Pessoa, S. d. A. (2007, July). The effects of longevity and distortions on education and retirement. Review of Economic Dynamics, 10(3), 472-493. doi: 10.1016/j.red.2007.01.003

Grantham-McGregor, S., Cheung, Y. B., Cueto, S., Glewwe, P., Richter, L., Strupp, B. \& the International Child Development Steering Group. (2007). Developmental potential in the first 5 years for children in developing countries. Lancet, 369(9555), 60-70. doi: 10.1016/S0140-6736(07)60032-4

Hall, R. E., \& Jones, C. I. (1999, February). Why do some countries produce so much more output per worker than others? The Quarterly Journal of Economics, 114(1), 83-116. Disponivel em: http://www.jstor.org/stable/ 2586948

Heckman, J.J. (2011). The economics of inequality: The value of early childhood education. American Educator, 35(1), 31-35.

Heckman, J.J., \& Cunha, F. (2007, May). The technology of skill formation. American Economic Review, 97(2), 31-47. doi: 10.1257/aer.97.2.31

Heckman, J.J., Moon, S. H., Pinto, R., Savelyev, P. \& Yavitz, A. (2010, Jul). A new cost-benefit and rate of return analysis for the Perry Preschool Program: A summary (NBER Working Paper $\mathrm{N}^{0} 16180$ ). National Bureau of Economic Research. Disponivel em: http://www.nber.org/papers/w16180

Irwin, L. G., Siddiqi, A. \& Hertzman, C. (2007, June). Early child development:a powerful equalizer (Final Report for the World Health Organization's Commission on the Social Determinants of Health). Vancouver, BC: World Health Organization. Disponivel em: http://www.who.int/social_determinants/themes/ earlychilddevelopment/en/

Klenow, P., \& Rodríguez-Clare, A. (1997). The neoclassical revival in growth economics: Has it gone too far? In NBER Macroeconomics Annual 1997, volume 12 (pp. 73-114). MIT Press.

Majgaard, K., \& Mingat, A. (2012). Education in sub-saharan Africa: a comparative analysis. Washington, D.C.: The World Bank. doi: 10.1596/978-0-8213-8889-1 
Manuelli, R. E., \& Seshadri, A. (2005). Human capital and the wealth of nations (2005 Meeting Papers $\mathrm{N}^{0} 56$ ). Society for Economic Dynamics

Myers, R., \& de San Jorge, X. (1999, April). Childcare and early education services in low-income communities in Mexico City: patterns of use, availability, and choice (LCSHD Paper Series $\mathrm{N}^{0}$ 20936). Washington, DC: World Bank: Latin America and the Caribbean Regional Office. Disponível em: http://documents.worldbank.org/curated/en/1999/04/693204/childcare-early-education-services -low-income-communities-mexico-city-patterns-use-availability-choice

Psacharopoulos, G. (1994). Returns to investment in education: A global update. World Development, 22(9), 1325-1343. doi: 10.1016/0305-750X(94)90007-8

Restuccia, D., \& Vandenbroucke, G. (2013a). A century of human capital and hours. Economic Inquiry, 51(3), 1849-1866. doi: 10.1111/j.1465-7295.2012.00497.x

Restuccia, D., \& Vandenbroucke, G. (2013b). The evolution of education: A macroeconomic analysis. International Economic Review, 54(3), 915-936. doi: 10.1111/iere.12022

Restuccia, D., \& Vandenbroucke, G. (2013c, Jan). Explaining educational attainment across countries and over time (Working Paper $\mathrm{N}^{0}$ 469). University of Toronto, Department of Economics. Disponivel em: http:/| ideas.repec.org/p/tor/tecipa/tecipa-469.html

Rolnick, A., \& Grunewald, R. (2003). Early childhood development: Economic development with a high public return. The Region, 17(4), 6-12.

Schweinhart, L. J., Montie, J., Xiang, Z., Barnett, W. S., Belfield, C. R. \& Nores, M. (2005). The High/Scope Perry Preschool Study Through Age 40: Summary, conclusions, and frequently asked questions. HighScope Press

Young, M. E. (1996). Early child development: investing in the future. Washington, DC: The International Bank for Reconstruction and Development/The World Bank 


\section{A. APÊNDICE}

Tabela A-1. Calibração - África Subsaariana

\begin{tabular}{|c|c|c|c|c|c|c|c|c|c|c|}
\hline & \multicolumn{5}{|c|}{1960} & \multicolumn{5}{|c|}{2010} \\
\hline & $A_{1}^{*}$ & $\left(1+\tau_{H}\right)$ & $\left(1-\tau_{K}\right)$ & $\tau_{L}$ & $T_{r}$ & $A_{1}^{*}$ & $\left(1+\tau_{H}\right)$ & $\left(1-\tau_{K}\right)$ & $\tau_{L}$ & $T_{r}$ \\
\hline Estados Unidos & 1,00 & 0,41 & 0,54 & 0,98 & 28,49 & 1,00 & 0,16 & 0,63 & 0,98 & 18,77 \\
\hline Benin & 0,34 & 2,59 & 0,74 & 0,95 & 14,01 & 0,24 & 2,05 & 0,68 & 0,72 & 26,22 \\
\hline Botswana & 0,31 & 2,51 & 0,49 & 0,95 & 21,70 & 0,32 & 0,11 & 1,73 & 0,98 & 5,02 \\
\hline Burundi & 0,31 & 2,55 & 0,26 & 0,96 & 13,91 & 0,17 & 2,46 & 0,34 & 0,74 & 17,13 \\
\hline Camarões & 0,57 & 2,43 & 0,34 & 0,94 & 17,15 & 0,27 & 1,83 & 0,62 & 0,68 & 19,68 \\
\hline República Centro Africana & 0,40 & 2,60 & 0,55 & 0,96 & 11,63 & 0,22 & 2,15 & 0,32 & 0,71 & 16,54 \\
\hline República Democrática do Congo & 0,27 & 2,87 & 2,00 & 0,94 & 23,95 & 0,23 & 0,16 & 1,28 & 0,97 & 21,94 \\
\hline Costa do Marfim & 0,49 & 2,45 & 0,44 & 0,93 & 16,34 & 0,40 & 1,99 & 0,21 & 0,63 & 20,38 \\
\hline Gabão & 0,63 & 2,36 & 1,84 & 0,95 & 16,09 & 0,70 & 0,11 & 0,83 & 0,98 & 24,87 \\
\hline Gâmbia & 1,06 & 2,50 & 0,09 & 0,95 & 11,55 & 0,25 & 2,13 & 0,79 & 0,76 & 25,21 \\
\hline Gana & 0,51 & 2,48 & 1,17 & 0,95 & 21,90 & 0,24 & 0,53 & 0,79 & 0,91 & 22,55 \\
\hline Quênia & 0,44 & 2,29 & 0,51 & 0,94 & 21,49 & 0,22 & 1,90 & 0,62 & 0,63 & 25,51 \\
\hline Lesoto & 0,44 & 2,29 & 0,06 & 0,91 & 17,39 & 0,18 & 1,41 & 1,09 & 0,68 & 15,38 \\
\hline Malawi & 0,19 & 2,51 & 0,83 & 0,94 & 11,98 & 0,13 & 2,10 & 1,39 & 0,72 & 19,67 \\
\hline Mali & 0,58 & 2,49 & 0,30 & 0,95 & 14,06 & 0,33 & 2,08 & 0,72 & 0,63 & 32,20 \\
\hline Mauritânia & 0,31 & 2,35 & 0,89 & 0,89 & 24,92 & 0,35 & 2,00 & 0,97 & 0,63 & 33,01 \\
\hline Ilhas Maurício & 0,39 & 2,44 & 1,73 & 0,89 & 33,29 & 0,52 & 0,17 & 0,93 & 0,98 & 26,99 \\
\hline Moçambique & 0,29 & 2,53 & 0,24 & 0,94 & 11,00 & 0,24 & 2,39 & 0,65 & 0,79 & 19,41 \\
\hline Namíbia & 0,64 & 2,23 & 0,77 & 0,89 & 23,28 & 0,42 & 0,19 & 1,11 & 0,97 & 26,56 \\
\hline Níger & 0,62 & 2,54 & 0,41 & 0,94 & 18,69 & 0,20 & 2,27 & 0,93 & 0,74 & 32,74 \\
\hline Ruanda & 0,78 & 2,49 & 0,09 & 0,96 & 14,50 & 0,24 & 2,23 & 0,54 & 0,78 & 23,57 \\
\hline Senegal & 0,71 & 2,37 & 0,20 & 0,92 & 14,52 & 0,22 & 2,02 & 0,98 & 0,75 & 26,34 \\
\hline África do Sul & 0,64 & 2,15 & 0,76 & 0,79 & 26,13 & 0,51 & 0,07 & 0,81 & 0,98 & 20,56 \\
\hline Tanzânia & 0,19 & 2,01 & 0,69 & 0,95 & 14,26 & 0,17 & 2,15 & 0,93 & 0,74 & 18,98 \\
\hline Togo & 0,43 & 2,48 & 0,46 & 0,96 & 17,73 & 0,16 & 2,06 & 0,62 & 0,72 & 17,14 \\
\hline Uganda & 0,53 & 2,47 & 0,19 & 0,94 & 17,78 & 0,23 & 2,01 & 0,57 & 0,67 & 24,18 \\
\hline Zâmbia & 0,51 & 2,37 & 0,45 & 0,93 & 17,47 & 0,27 & 1,78 & 0,60 & 0,68 & 19,17 \\
\hline
\end{tabular}

* Os valores estão relativos aos Estados Unidos.

Tabela A-2. Calibração - Europa

\begin{tabular}{|c|c|c|c|c|c|c|c|c|c|c|}
\hline & \multicolumn{5}{|c|}{1960} & \multicolumn{5}{|c|}{2010} \\
\hline & $A_{1}^{*}$ & $\left(1+\tau_{H}\right)$ & $\left(1-\tau_{K}\right)$ & $\tau_{L}$ & $T_{r}$ & $A_{1}^{*}$ & $\left(1+\tau_{H}\right)$ & $\left(1-\tau_{K}\right)$ & $\tau_{L}$ & $T_{r}$ \\
\hline Estados Unidos & 1,00 & 0,41 & 0,54 & 0,98 & 28,49 & 1,00 & 0,16 & 0,63 & 0,98 & 18,77 \\
\hline Áustria & 0,96 & 0,83 & 0,82 & 0,98 & 29,50 & 1,11 & 0,20 & 0,74 & 0,98 & 24,91 \\
\hline Bélgica & 0,77 & 0,52 & 0,85 & 0,98 & 31,07 & 1,01 & 0,16 & 0,82 & 0,98 & 28,89 \\
\hline Chipre & 0,41 & 1,65 & 1,24 & 0,94 & 35,01 & 0,69 & 0,20 & 0,77 & 0,98 & 21,39 \\
\hline Dinamarca & 0,77 & 0,61 & 0,71 & 0,98 & 27,41 & 1,03 & 0,20 & 0,70 & 0,98 & 22,02 \\
\hline Finlândia & 0,66 & 0,75 & 1,11 & 0,98 & 25,78 & 0,96 & 0,19 & 0,81 & 0,98 & 24,80 \\
\hline França & 1,01 & 0,77 & 0,74 & 0,98 & 32,45 & 1,01 & 0,16 & 0,69 & 0,98 & 29,23 \\
\hline Grécia & 0,50 & 0,55 & 0,81 & 0,98 & 26,98 & 0,93 & 0,15 & 0,63 & 0,98 & 29,65 \\
\hline Islândia & 0,96 & 0,57 & 0,90 & 0,98 & 35,99 & 1,09 & 0,21 & 0,51 & 0,98 & 17,58 \\
\hline Irlanda & 0,65 & 0,44 & 0,66 & 0,98 & 30,15 & 1,07 & 0,16 & 0,53 & 0,98 & 24,81 \\
\hline Itália & 0,73 & 0,75 & 1,08 & 0,98 & 29,91 & 0,99 & 0,15 & 0,83 & 0,98 & 35,07 \\
\hline Holanda & 1,05 & 0,57 & 0,76 & 0,98 & 36,68 & 1,05 & 0,19 & 0,64 & 0,98 & 20,68 \\
\hline Noruega & 0,73 & 0,54 & 1,10 & 0,98 & 32,60 & 1,08 & 0,18 & 0,78 & 0,98 & 18,38 \\
\hline Portugal & 0,66 & 2,29 & 0,79 & 0,93 & 32,06 & 0,81 & 0,22 & 0,80 & 0,98 & 25,14 \\
\hline Romênia & 0,26 & 2,61 & 0,65 & 0,93 & 22,04 & 0,51 & 0,16 & 0,74 & 0,98 & 22,66 \\
\hline Espanha & 0,89 & 2,28 & 0,69 & 0,94 & 35,75 & 0,84 & 0,19 & 0,84 & 0,98 & 25,24 \\
\hline Suécia & 0,90 & 0,70 & 0,75 & 0,98 & 25,80 & 1,02 & 0,19 & 0,61 & 0,98 & 20,34 \\
\hline Reino Unido & 1,28 & 0,70 & 0,54 & 0,98 & 27,81 & 1,17 & 0,20 & 0,57 & 0,98 & 25,01 \\
\hline
\end{tabular}


Tabela A-3. Variáveis endógenas do modelo - África Subsaariana

\begin{tabular}{|c|c|c|c|c|c|c|c|c|c|c|}
\hline & \multicolumn{5}{|c|}{1960} & \multicolumn{5}{|c|}{2010} \\
\hline & $x$ & $q$ & $k_{1}$ & $k_{2}$ & $l_{1}$ & $x$ & $q$ & $k_{1}$ & $k_{2}$ & $l_{1}$ \\
\hline Estados Unidos & 1,00 & 1,00 & 1,00 & 1,00 & 1,000 & 1,00 & 1,00 & 1,00 & 1,00 & 1,000 \\
\hline Benin & 0,03 & 0,21 & 0,28 & 0,28 & 1,007 & 0,25 & 0,11 & 0,10 & 0,10 & 0,994 \\
\hline Botswana & 0,07 & 0,15 & 0,12 & 0,12 & 1,006 & 0,81 & 0,30 & 0,81 & 0,81 & 0,989 \\
\hline Burundi & 0,03 & 0,10 & 0,04 & 0,04 & 1,007 & 0,16 & 0,04 & 0,02 & 0,02 & 1,000 \\
\hline Camarões & 0,06 & 0,32 & 0,19 & 0,19 & 1,005 & 0,44 & 0,12 & 0,11 & 0,11 & 0,986 \\
\hline República Centro Africana & 0,02 & 0,24 & 0,23 & 0,23 & 1,008 & 0,20 & 0,06 & 0,02 & 0,02 & 0,994 \\
\hline República Democrática do Congo & 0,06 & 0,27 & 0,99 & 0,99 & 1,006 & 0,43 & 0,15 & 0,28 & 0,28 & 0,990 \\
\hline Costa do Marfim & 0,05 & 0,29 & 0,22 & 0,22 & 1,005 & 0,30 & 0,12 & 0,03 & 0,03 & 0,984 \\
\hline Gabão & 0,07 & 1,00 & 3,64 & 3,64 & 1,006 & 0,67 & 0,67 & 0,87 & 0,87 & 0,987 \\
\hline Gâmbia & 0,02 & 0,38 & 0,05 & 0,05 & 1,007 & 0,18 & 0,13 & 0,14 & 0,14 & 0,999 \\
\hline Gana & 0,06 & 0,54 & 1,20 & 1,20 & 1,006 & 0,51 & 0,12 & 0,13 & 0,13 & 0,989 \\
\hline Quênia & 0,09 & 0,27 & 0,24 & 0,24 & 1,004 & 0,50 & 0,09 & 0,08 & 0,08 & 0,983 \\
\hline Lesoto & 0,20 & 0,07 & 0,01 & 0,01 & 1,001 & 0,55 & 0,09 & 0,14 & 0,14 & 0,979 \\
\hline Malawi & 0,06 & 0,10 & 0,14 & 0,14 & 1,006 & 0,27 & 0,06 & 0,12 & 0,12 & 0,994 \\
\hline Mali & 0,01 & 0,30 & 0,15 & 0,15 & 1,007 & 0,14 & 0,19 & 0,20 & 0,20 & 0,988 \\
\hline Mauritânia & 0,10 & 0,21 & 0,33 & 0,33 & 1,001 & 0,31 & 0,24 & 0,35 & 0,35 & 0,986 \\
\hline Ilhas Maurício & 0,30 & 0,44 & 1,45 & 1,45 & 1,000 & 0,49 & 0,44 & 0,62 & 0,62 & 0,999 \\
\hline Moçambique & 0,05 & 0,09 & 0,03 & 0,03 & 1,006 & 0,08 & 0,11 & 0,10 & 0,10 & 1,007 \\
\hline Namíbia & 0,26 & 0,61 & 0,86 & 0,86 & 1,000 & 0,41 & 0,35 & 0,60 & 0,60 & 0,993 \\
\hline Níger & 0,02 & 0,40 & 0,28 & 0,28 & 1,007 & 0,09 & 0,10 & 0,14 & 0,14 & 1,000 \\
\hline Ruanda & 0,04 & 0,24 & 0,04 & 0,04 & 1,007 & 0,19 & 0,09 & 0,07 & 0,07 & 1,002 \\
\hline Senegal & 0,12 & 0,33 & 0,11 & 0,11 & 1,003 & 0,30 & 0,11 & 0,16 & 0,16 & 0,996 \\
\hline África do Sul & 0,57 & 0,61 & 0,86 & 0,86 & 0,993 & 0,90 & 0,40 & 0,49 & 0,49 & 0,973 \\
\hline Tanzânia & 0,10 & 0,08 & 0,09 & 0,09 & 1,005 & 0,33 & 0,08 & 0,10 & 0,10 & 0,997 \\
\hline Togo & 0,02 & 0,24 & 0,19 & 0,19 & 1,007 & 0,34 & 0,05 & 0,04 & 0,04 & 0,994 \\
\hline Uganda & 0,06 & 0,20 & 0,06 & 0,06 & 1,005 & 0,36 & 0,09 & 0,07 & 0,07 & 0,988 \\
\hline Zâmbia & 0,15 & 0,31 & 0,24 & 0,24 & 1,003 & 0,48 & 0,13 & 0,11 & 0,11 & 0,986 \\
\hline
\end{tabular}

* Os valores estão relativos aos Estados Unidos.

Tabela A-4. Variáveis endógenas do modelo - Europa

\begin{tabular}{|c|c|c|c|c|c|c|c|c|c|c|}
\hline & \multicolumn{5}{|c|}{1960} & \multicolumn{5}{|c|}{2010} \\
\hline & $x$ & $q$ & $k_{1}$ & $k_{2}$ & $l_{1}$ & $x$ & $q$ & $k_{1}$ & $k_{2}$ & $l_{1}$ \\
\hline Estados Unidos & 1,00 & 1,00 & 1,00 & 1,00 & 1,000 & 1,00 & 1,00 & 1,00 & 1,00 & 1,00 \\
\hline Áustria & 0,27 & 1,20 & 1,88 & 1,88 & 1,004 & 0,59 & 1,29 & 1,53 & 1,53 & 1,003 \\
\hline Bélgica & 0,63 & 0,87 & 1,39 & 1,39 & 1,001 & 0,77 & 1,18 & 1,56 & 1,56 & 0,999 \\
\hline Chipre & 0,41 & 0,40 & 0,93 & 0,93 & 1,002 & 0,63 & 0,62 & 0,74 & 0,74 & 1,003 \\
\hline Dinamarca & 0,64 & 0,78 & 1,04 & 1,04 & 1,002 & 0,62 & 1,11 & 1,23 & 1,23 & 1,003 \\
\hline Finlândia & 0,41 & 0,79 & 1,68 & 1,68 & 1,004 & 0,64 & 1,08 & 1,39 & 1,39 & 1,002 \\
\hline França & 0,29 & 1,23 & 1,74 & 1,74 & 1,004 & 0,74 & 1,07 & 1,17 & 1,17 & 0,999 \\
\hline Grécia & 0,66 & 0,43 & 0,64 & 0,64 & 1,001 & 0,79 & 0,88 & 0,87 & 0,87 & 0,997 \\
\hline Islândia & 0,52 & 1,25 & 2,18 & 2,18 & 1,002 & 0,65 & 1,02 & 0,81 & 0,81 & 1,005 \\
\hline Irlanda & 0,80 & 0,56 & 0,67 & 0,67 & 1,000 & 0,84 & 1,00 & 0,82 & 0,82 & 1,000 \\
\hline Itália & 0,35 & 0,91 & 1,88 & 1,88 & 1,004 & 0,68 & 1,16 & 1,54 & 1,54 & 0,997 \\
\hline Holanda & 0,54 & 1,32 & 1,91 & 1,91 & 1,001 & 0,72 & 1,09 & 1,10 & 1,10 & 1,003 \\
\hline Noruega & 0,69 & 0,92 & 1,95 & 1,95 & 1,002 & 0,84 & 1,28 & 1,62 & 1,62 & 1,003 \\
\hline Portugal & 0,22 & 0,65 & 0,96 & 0,96 & 1,003 & 0,46 & 0,82 & 1,04 & 1,04 & 1,004 \\
\hline Romênia & 0,37 & 0,13 & 0,14 & 0,14 & 1,003 & 0,74 & 0,37 & 0,42 & 0,42 & 0,997 \\
\hline Espanha & 0,22 & 0,95 & 1,23 & 1,23 & 1,004 & 0,68 & 0,89 & 1,18 & 1,18 & 1,002 \\
\hline Suécia & 0,57 & 1,03 & 1,47 & 1,47 & 1,003 & 0,76 & 1,00 & 0,96 & 0,96 & 1,003 \\
\hline Reino Unido & 0,48 & 1,47 & 1,50 & 1,50 & 1,003 & 0,58 & 1,20 & 1,08 & 1,08 & 1,003 \\
\hline
\end{tabular}


Tabela A-5. Política educacional para os países subsaarianos em 2010 - Subsídio educacional subsaariano igual ao subsídio educacional europeu médio para educação pré-escolar e para a formal. ${ }^{*}$

\begin{tabular}{|c|c|c|c|c|c|}
\hline & \multicolumn{3}{|c|}{ Valores relativos à simulação de 2010} & \multirow[b]{2}{*}{ Razão } & \multirow{2}{*}{$\frac{1+\tau_{H}^{\text {Europa }}}{1+\tau_{H}}$} \\
\hline & $y$ & $x$ & $T_{s}$ & & \\
\hline Benin & 2,01 & 13,64 & 2,55 & & 0,09 \\
\hline Botswana & 0,73 & 0,45 & 0,66 & & 1,65 \\
\hline Burundi & 2,55 & 22,73 & 3,71 & & 0,07 \\
\hline Camarões & 1,76 & 9,62 & 1,94 & & 0,10 \\
\hline República Centro Africana & 2,08 & 15,70 & 2,87 & & 0,08 \\
\hline República Democrática do Congo & 0,94 & 0,83 & 0,90 & & 1,12 \\
\hline Costa do Marfim & 1,71 & 10,75 & 2,11 & & 0,09 \\
\hline Gabão & 0,74 & 0,44 & 0,63 & & 1,68 \\
\hline Gâmbia & 2,23 & 17,06 & 3,11 & & 0,09 \\
\hline Gana & 1,51 & 3,54 & 1,61 & & 0,34 \\
\hline Quênia & 1,70 & 9,23 & 1,84 & & 0,10 \\
\hline $\begin{array}{l}\text { Lesoto } \\
\text { Leto }\end{array}$ & 1,55 & 6,82 & 1,67 & & 0,13 \\
\hline Malawi & 2,04 & 13,77 & 2,51 & & 0,09 \\
\hline Mali & 1,58 & 12,04 & 2,46 & & 0,09 \\
\hline Mauritânia & 1,65 & 10,26 & 2,02 & & 0,09 \\
\hline Ilhas Maurício & 0,96 & 0,91 & 0,95 & & 1,05 \\
\hline Moçambique & 2,53 & 28,39 & 5,15 & & 0,08 \\
\hline Namíbia & 1,02 & 1,06 & 1,03 & & 0,96 \\
\hline Níger & 1,97 & 19,34 & 3,74 & & 0,08 \\
\hline Ruanda & 2,63 & 20,61 & 3,50 & & 0,08 \\
\hline Senegal & 2,13 & 13,67 & 2,51 & & 0,09 \\
\hline África do Sul & 0,63 & 0,25 & 0,49 & & 2,58 \\
\hline Tanzânia & 2,31 & 14,98 & 2,58 & & 0,08 \\
\hline Togo & 2,15 & 13,52 & 2,43 & & 0,09 \\
\hline Uganda & 1,84 & 11,20 & 2,12 & & 0,09 \\
\hline Zâmbia & 1,77 & 9,33 & 1,90 & & 0,10 \\
\hline
\end{tabular}

Tabela A-6. Política educacional para os países subsaarianos em 2010 - Subsídio para a educação formal subsaariana igual ao subsídio médio para a educação formal dos países europeus. *

\begin{tabular}{|c|c|c|c|c|c|}
\hline & \multicolumn{3}{|c|}{ Valores relativos à simulação de 2010} & \multirow[b]{2}{*}{ Razão } & \multirow{2}{*}{$\frac{1+\tau_{H}^{\text {Europa }}}{1+\tau_{H}}$} \\
\hline & $y$ & $x$ & $T_{S}$ & & \\
\hline Benin & 1,13 & 1,31 & 1,42 & & 0,09 \\
\hline Botswana & 0,95 & 0,92 & 0,90 & & 1,65 \\
\hline Burundi & 1,22 & 1,55 & 1,78 & & 0,07 \\
\hline Camarões & 1,07 & 1,17 & 1,22 & & 0,10 \\
\hline República Centro Africana & 1,15 & 1,38 & 1,53 & & 0,08 \\
\hline República Democrática do Congo & 0,99 & 0,97 & 0,97 & & 1,12 \\
\hline Costa do Marfim & 1,08 & 1,20 & 1,28 & & 0,09 \\
\hline Gabão & 0,95 & 0,91 & 0,89 & & 1,68 \\
\hline Gâmbia & 1,17 & 1,43 & 1,60 & & 0,09 \\
\hline Gana & 1,06 & 1,12 & 1,16 & & 0,34 \\
\hline Quênia & 1,06 & 1,14 & 1,19 & & 0,10 \\
\hline Lesoto & 1,05 & 1,11 & 1,14 & & 0,13 \\
\hline Malawi & 1,13 & 1,30 & 1,40 & & 0,09 \\
\hline Mali & 1,08 & 1,27 & 1,40 & & 0,09 \\
\hline Mauritânia & 1,07 & 1,18 & 1,25 & & 0,09 \\
\hline Ilhas Maurício & 0,99 & 0,99 & 0,98 & & 1,05 \\
\hline Moçambique & 1,25 & 1,78 & 2,21 & & 0,08 \\
\hline Namíbia & 1,00 & 1,01 & 1,01 & & 0,96 \\
\hline Níger & 1,16 & 1,53 & 1,81 & & 0,08 \\
\hline Ruanda & 1,22 & 1,52 & 1,71 & & 0,08 \\
\hline Senegal & 1,13 & 1,30 & 1,40 & & 0,09 \\
\hline África do Sul & 0,94 & 0,88 & 0,86 & & 2,58 \\
\hline Tanzânia & 1,15 & 1,31 & 1,41 & & 0,08 \\
\hline Togo & 1,13 & 1,28 & 1,37 & & 0,09 \\
\hline Uganda & 1,09 & 1,21 & 1,28 & & 0,09 \\
\hline Zâmbia & 1,07 & 1,16 & 1,21 & & 0,10 \\
\hline
\end{tabular}


Tabela A-7. Política educacional para os países subsaarianos em 2010 - Subsídio para a educação pré-escolar subsaariana igual ao subsídio médio para a educação pré-escolar dos países europeus. *

\begin{tabular}{|c|c|c|c|c|c|}
\hline & \multicolumn{3}{|c|}{ Valores relativos à simulação de 2010} & \multirow[b]{2}{*}{ Razão } & \multirow{2}{*}{$\frac{1+\tau_{H}^{\text {Europa }}}{1+\tau_{H_{c}}}$} \\
\hline & $y$ & $x$ & $T_{S}$ & & \\
\hline Benin & 1,94 & 12,58 & 2,29 & & 0,09 \\
\hline Botswana & 0,78 & 0,51 & 0,76 & & 1,65 \\
\hline Burundi & 2,43 & 20,43 & 3,23 & & 0,07 \\
\hline Camarões & 1,73 & 9,15 & 1,81 & & 0,10 \\
\hline República Centro Africana & 2,00 & 14,27 & 2,53 & & 0,08 \\
\hline República Democrática do Congo & 0,95 & 0,86 & 0,93 & & 1,12 \\
\hline Costa do Marfim & 1,68 & 10,07 & 1,93 & & 0,09 \\
\hline Gabão & 0,79 & 0,50 & 0,75 & & 1,68 \\
\hline Gâmbia & 2,13 & 15,41 & 2,72 & & 0,09 \\
\hline Gana & 1,47 & 3,35 & 1,50 & & 0,34 \\
\hline Quênia & 1,67 & 8,84 & 1,73 & & 0,10 \\
\hline Lesoto & 1,52 & 6,54 & 1,58 & & 0,13 \\
\hline Malawi & 1,98 & 12,78 & 2,27 & & 0,09 \\
\hline Mali & 1,54 & 10,80 & 2,12 & & 0,09 \\
\hline Mauritânia & 1,62 & 9,63 & 1,86 & & 0,09 \\
\hline Ilhas Maurício & 0,97 & 0,93 & 0,96 & & 1,05 \\
\hline Moçambique & 2,33 & 23,53 & 4,05 & & 0,08 \\
\hline Namíbia & 1,02 & 1,05 & 1,02 & & 0,96 \\
\hline Níger & 1,86 & 16,33 & 2,99 & & 0,08 \\
\hline Ruanda & 2,51 & 18,76 & 3,10 & & 0,08 \\
\hline Senegal & 2,06 & 12,75 & 2,29 & & 0,09 \\
\hline África do Sul & 0,70 & 0,31 & 0,65 & & 2,58 \\
\hline Tanzânia & 2,23 & 14,06 & 2,37 & & 0,08 \\
\hline Togo & 2,09 & 12,69 & 2,23 & & 0,09 \\
\hline Uganda & 1,79 & 10,56 & 1,96 & & 0,09 \\
\hline Zâmbia & 1,74 & 8,90 & 1,79 & & 0,10 \\
\hline
\end{tabular}

Tabela A-8. Análise quantitativa para os países subsaarianos em 2010 - aumento de 10\% na expectativa de vida dos países subsaarianos.

\begin{tabular}{|c|c|c|c|c|}
\hline & \multicolumn{3}{|c|}{ Valores relativos à simulação de 2010} & \multirow[b]{2}{*}{$\begin{array}{l}\text { Expectativa de vida } \\
\text { em } 2010\end{array}$} \\
\hline & $y$ & $x$ & $T_{S}$ & \\
\hline Benin & 1,05 & 1,13 & 1,11 & 58,75 \\
\hline Botswana & 1,05 & 1,11 & 1,09 & 46,44 \\
\hline Burundi & 1,06 & 1,15 & 1,13 & 52,62 \\
\hline Camarões & 1,05 & 1,12 & 1,10 & 53,69 \\
\hline República Centro Africana & 1,06 & 1,15 & 1,13 & 48,10 \\
\hline República Democrática do Congo & 1,05 & 1,12 & 1,10 & 57,20 \\
\hline Costa do Marfim & 1,05 & 1,13 & 1,11 & 49,68 \\
\hline Gabão & 1,05 & 1,10 & 1,08 & 62,29 \\
\hline Gâmbia & 1,05 & 1,14 & 1,12 & 58,13 \\
\hline Gana & 1,05 & 1,11 & 1,09 & 60,60 \\
\hline Quênia & 1,05 & 1,11 & 1,09 & 59,55 \\
\hline Lesoto & 1,05 & 1,12 & 1,09 & 47,48 \\
\hline Malawi & 1,05 & 1,14 & 1,11 & 53,47 \\
\hline Mali & 1,04 & 1,14 & 1,12 & 53,77 \\
\hline Mauritânia & 1,04 & 1,12 & 1,10 & 61,02 \\
\hline Ilhas Maurício & 1,05 & 1,11 & 1,09 & 72,97 \\
\hline Moçambique & 1,05 & 1,16 & 1,14 & 49,14 \\
\hline Namíbia & 1,05 & 1,12 & 1,09 & 62,48 \\
\hline Níger & 1,04 & 1,14 & 1,13 & 56,99 \\
\hline Ruanda & 1,06 & 1,14 & 1,12 & 62,21 \\
\hline Senegal & 1,05 & 1,13 & 1,11 & 62,84 \\
\hline África do Sul & 1,04 & 1,10 & 1,07 & 54,39 \\
\hline Tanzânia & 1,06 & 1,13 & 1,11 & 59,18 \\
\hline Togo & 1,06 & 1,13 & 1,11 & 55,47 \\
\hline Uganda & 1,05 & 1,13 & 1,10 & 57,30 \\
\hline Zâmbia & 1,05 & 1,12 & 1,09 & 54,53 \\
\hline
\end{tabular}


Tabela A-9. Análise quantitativa para os países subsaarianos em 2010 - aumento de 10\% na PTF dos países subsaarianos.

\begin{tabular}{lccc}
\hline & \multicolumn{2}{c}{ Valores relativos à simulação de 2010} \\
\cline { 2 - 4 } & $y$ & $x$ & $T_{S}$ \\
\hline Benin & 1,178 & 1,014 & 1,009 \\
Botswana & 1,177 & 1,011 & 1,005 \\
Burundi & 1,180 & 1,018 & 1,013 \\
Camarões & 1,177 & 1,012 & 1,006 \\
República Centro Africana & 1,178 & 1,015 & 1,010 \\
República Democrática do Congo & 1,177 & 1,012 & 1,007 \\
Costa do Marfim & 1,177 & 1,012 & 1,007 \\
Gabão & 1,177 & 1,011 & 1,005 \\
Gâmbia & 1,179 & 1,016 & 1,011 \\
Gana & 1,178 & 1,012 & 1,006 \\
Quênia & 1,177 & 1,011 & 1,006 \\
Lesoto & 1,176 & 1,010 & 1,005 \\
Malawi & 1,178 & 1,014 & 1,009 \\
Mali & 1,176 & 1,013 & 1,008 \\
Mauritânia & 1,176 & 1,012 & 1,006 \\
Ilhas Maurício & 1,180 & 1,015 & 1,008 \\
Moçambique & 1,178 & 1,018 & 1,014 \\
Namíbia & 1,178 & 1,013 & 1,007 \\
Níger & 1,177 & 1,016 & 1,012 \\
Ruanda & 1,180 & 1,018 & 1,013 \\
Senegal & 1,179 & 1,015 & 1,009 \\
África do Sul & 1,175 & 1,009 & 1,003 \\
Tanzânia & 1,179 & 1,015 & 1,010 \\
Togo & 1,179 & 1,015 & 1,009 \\
Uganda & 1,177 & 1,013 & 1,007 \\
Zâmbia & 1,177 & 1,012 & 1,006 \\
\hline
\end{tabular}

